\title{
A methodology for creating and validating psychological stories for conveying and measuring psychological traits
}

\author{
Kirsten A. Smith ${ }^{1}$ (D) Matt Dennis ${ }^{2}$. Judith Masthoff ${ }^{3,4} \cdot$ Nava Tintarev $^{5}$ \\ Received: 27 February 2018 / Accepted in revised form: 17 January 2019 / Published online: 19 March 2019 \\ (c) The Author(s) 2019
}

\begin{abstract}
Personality impacts all areas of our lives; it governs who we are and how we react to life's challenges. Personalized systems that adapt to end users should take into account the user's personality to perform well. Several methodologies (e.g. User-as-Wizard, indirect studies) that use personality adaptation require first for personality to be conveyed to the participant; this has few validated approaches. Furthermore, measuring personality is often time consuming, prone to response bias (e.g. using questionnaires) or data intensive (e.g. using behaviour or text mining). This paper presents a methodology for creating and validating stories to convey psychological traits and for using such stories with a personality slider scale to measure these traits. We present the validation of the scale and evaluate its reliability. To evidence the validity of the methodology, we outline studies where the stories and scale have been effectively applied (in recommender systems, intelligent tutoring systems, and persuasive systems).
\end{abstract}

Keywords Empirical methodology · Personality · Personality measurement · Research tools

\section{Introduction}

Personality- “a person's nature or disposition; the qualities that give one's character individuality" _ _ is a key area of research in user modelling and user adaptive systems. One of the most popular ways to describe and measure personality is trait theorywhere a person is assessed against one or more factors (e.g. 'Conscientiousness' or

\footnotetext{
1 http://www.chambers.co.uk.

$\triangle$ Kirsten A. Smith

kirsten.smith@soton.ac.uk

1 University of Southampton, Southampton, UK

2 University of Portsmouth, Portsmouth, UK

3 University of Aberdeen, Aberdeen, UK

4 Utrecht University, Utrecht, Netherlands

5 TU Delft, Delft, Netherlands
} 
'Agreeableness'). These measurable differences in how people interact with the world are prime targets for providing users with an appropriately tailored user experience. However, to facilitate these tailored user experiences, researchers first need to discover which aspects of personality are important for adaptation, and how to tailor experience to them. ${ }^{2}$

One approach would be to measure users' personality and ask them to use the system or evaluate its features. However, as noted in Paramythis et al.'s (2010) discussion on layered evaluation, one issue with using a user-based study for an adaptive system is that adaptation takes time, often more than is available during a study. One solution they advocate is an indirect study, where the user model is given to participants and they perform the task on behalf of a third party. This allows researchers to control the characteristics of the imaginary user, avoiding the time delay needed for populating the user model from actual user interactions with the system. An indirect study also ensures that the input to an adaptation layer is perfect, making it very suitable for layered evaluations. Indirect studies may also be required for other reasons - for example, they are needed when it is difficult to recruit a large enough number of target participants, such as in the work by Smith et al. (2016) for skin cancer patients.

Another way to investigate adaptation strategies and discover pertinent personality traits is by using a User-as-wizard approach (Masthoff 2006; Paramythis et al. 2010), which uses human behaviour to inspire the algorithms needed in an adaptive system. In a User-as-Wizard study, participants are given the same information the system would have, and are asked to perform the system's task. Normally, participants will deal with fictional users, which allows us to study multiple participants dealing with the same user, controlling exactly what information participants get.

When using a User-as-Wizard or indirect approach for adaptation to personality research, the simulated user's personality needs to be conveyed. However, there is a paucity of easy, validated ways to convey or represent the personality of a third party to participants. One option is to use real people, allowing participants to interact with a person with the desired trait. However, this is hard to control as it is hard to ensure participants adapt to personality instead of, for example, current affective state. Participants would have to spend considerable time with the individual to perceive their personality. Another option is to ask participants to "imagine a user who is extravert" or provide statements such as "John is neurotic". This approach is unlikely to elicit empathy from participants due to a lack of context about the simulated user and could possibly be overlooked when placed with other data, such as test scores.

This is a non-trivial research problem: how to provide enough information about the personality of a simulated user for participants to identify and empathise with them, without making the simulated user seem one-dimensional and implausible. This paper details a methodology for conveying personality using validated personality stories.

In addition to conveying personality, these stories can be used as part of an alternative method of measuring personality.

\footnotetext{
2 Personality is only one of many user characteristics that may impact user behaviour (Okpo et al. 2018). Other user characteristics include cognitive and physical ability (Loitsch et al. 2017), knowledge (Pelánek 2017), interests (Piao and Breslin 2018), and affect (Mizgajski and Morzy 2018; Grawemeyer et al. 2017). Additionally, situational factors, norms, and roles may moderate the impact of personality (Harland et al. 2007). Researchers normally investigate adaptation to personality together with other factors.
} 
Reliable and efficient personality measurement is still largely an open challenge. Whilst validated personality tests exist, completing them may create an overhead that is unacceptable to users: personality tests range from the Five Item Personality Inventory (FIPI test) (Gosling et al. 2003) to the 300-item International Personality Item Pool (IPIP-NEO) (Goldberg et al. 2006). A problem with questionnaires is response bias, in particular, the bias introduced by acquiescence or 'yea-saying'-the tendency of individuals to consistently agree with survey items regardless of their content (Jackson and Messick 1958). This is an issue with many personality trait questionnaires, and was one reason why a new version of the Big Five Inventory (BFI-2) was produced recently (Soto and John 2017). Questionnaires may also be undesirable for reasons described later. Current approaches to unobtrusively measure personality include analysis of blogs (e.g. Nowson and Oberlander 2007; Iacobelli et al. 2011), users' social media content (e.g. Facebook, Twitter) (Gao et al. 2013; Golbeck et al. 2011; Quercia et al. 2011) or social media behaviour (e.g. Amichai-Hamburger and Vinitzky 2010; Ross et al. 2009). These indirect approaches are however still far less reliable than direct approaches.

Using the personality stories as a basis, we propose an alternative and light-weight approach for reliably measuring personality, using so-called personality sliders with the stories at the slider ends, which is faster than completing many personality tests. We describe how identification with the people in personality stories can easily and engagingly be used to measure user personality. Personality sliders provide a broad characterisation of a personality trait, whilst at the same time making it less salient to participants what they are asked about. Personality sliders take about a minute to complete per trait (assuming an average reading speed), so are fast to administer and may save time particularly:

- In studies or systems that require a user characteristic for which short questionnaires do not yet exist. Short questionnaires only exist for some personality traits (most noticeably the Five Factor Model), whilst the slider approach can be used for any personality trait as well as other user characteristics. Of course, the personality stories are created from questionnaire items, and using more items increases reading time. However, only one decision/interaction is required per trait (compared to one per item for the questionnaires), reducing cognitive load and decision time.

- In studies that require both the measurement of the participants' personality and the portrayal of the personality of fictional people-e.g. looking at the impact of self-similar personality on book recommendations for fictional users. Participants only need to read the stories once, so $1 \mathrm{~min}$ suffices to both complete the personality test and portray two fictional users' personality.

- In studies or systems that require obtaining personality measurements for multiple people provided by one person. For example, in Moncur et al. (2014), automated messages about babies in intensive care to their parents' social network were adapted to individual receivers' characteristics. This may require a parent to indicate the emotional stability of the people closest to them. Using the personality sliders, participants only have to read the stories once, and then only need to make one decision/interaction per personality trait per person. 
Another advantage of using personality sliders is that it reduces response bias. Using the personality story sliders, participants need to judge which person they resemble more, so are not agreeing/disagreeing with individual items, removing bias due to acquiescence. Multi-item surveys also tend to suffer from straight-lining. Straightlining occurs when participants give identical (or nearly identical) responses to items in a battery of questions using the same response scale (Zhang and Conrad 2014). Requiring only one interaction per trait (as in the sliders) mitigates this. Finally, personality sliders provide a higher granularity of personality, as the sliders provide continuous rather than interval data, whilst most personality tests are restricted to a small number of points. This also means that the data is more appropriate for parametric analysis than traditional likert data.

To evidence the practical value of our methodology for conveying and measuring personality, we show how the personality stories and personality sliders have been successfully used in many of our studies (see Sect. 6).

\subsection{Overview of methodology}

Our methodology for conveying and measuring personality traits using personality stories (see Fig. 1) consists of the following stages:

1. Creating short stories about a person to express distinct personality traits (their target trait): we use Resilience, Generalized Self-Efficacy, and those from the Five Factor model.

2. Iteratively validating the generated stories to ensure that the stories convey their target trait at high and low levels, and are able to robustly portray the desired trait

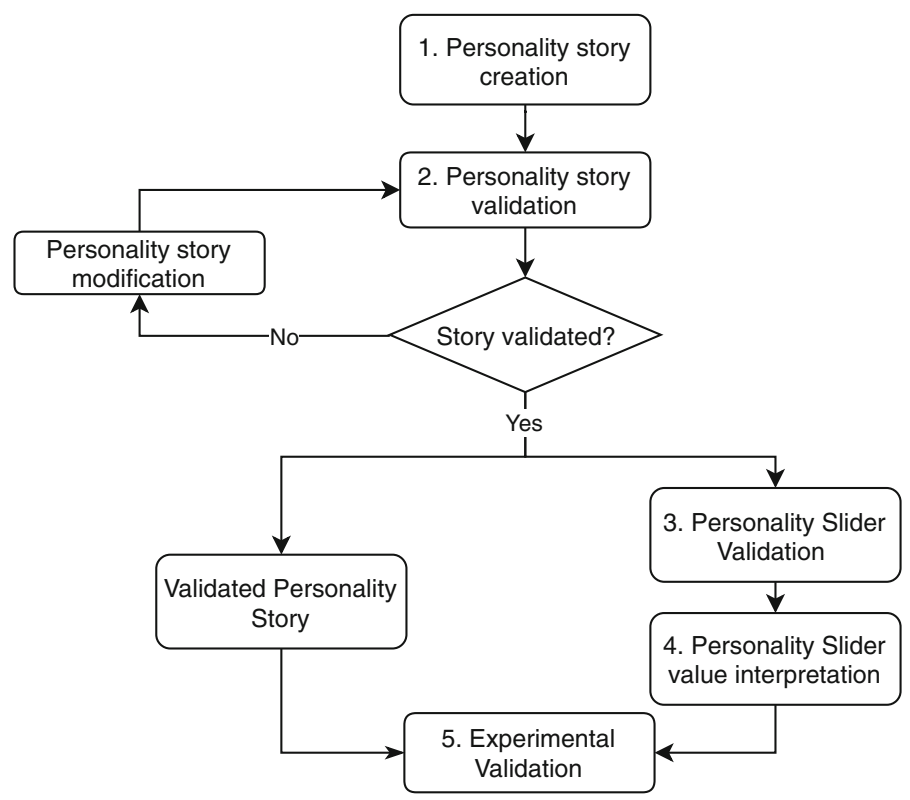

Fig. 1 The methodology used in this paper for personality slider development 
by asking people to fill out a personality questionnaire for the person in the story (different from the questionnaires used for story creation). Issues include both the case where the perceived score for a non-target trait (a personality trait other than the target trait) differs significantly between high and low story, and where the scores for these non-target traits lie outside a normative range. The pilots were conducted in the lab with later studies conducted using crowdsourcing for broader generalizability.

3. Validating the approach of measuring personality through stories by allowing users to pick which individual they are most like, using a slider. The values of these results were correlated with standardized personality tests for the same traits.

4. Outline how the slider values can be used to distinguish groups of users with distinct levels of personality traits. Before the sliders could be used in a system, or even applied experimentally to evaluate adaptation, we needed to define how to use the slider values. We summarise the advantages and disadvantages of the respective methods.

5. Validating the approach in an experiment where personality is likely to affect adaptation (i.e. use the stories in an experiment where you hypothesize that there ought to be an effect of personality). We tested the approach in multiple studies.

\subsection{Crowd sourcing participants}

We rely heavily on rapid questionnaire responses from a participant pool to iteratively validate personality stories. Where the number of unique participants required was small, we used convenience sampling. However, our participant pool was too small for Five Factor Model validation as many iterations were required (explained in Sect. 4.3). To expand our participant pool, we decided to use the crowd-sourcing service, Amazon Mechanical Turk (MT) (2012).

MT is helpful when requiring large numbers of participants for studies. However, valid concerns exist that data collected online may be of lower quality and requires robust validation methods. Many studies, such as those described by Weinberg et al. (2014) have tried to show the validity of using MT to collect research data. These studies have generally found that the quality of MT data is comparable to what would be collected from supervised lab experiments, if studies are carefully set up, explained, and controlled. We follow recommended best practice in our MT experimental design and procedures.

In our work we have obtained some insights into using crowd-sourcing to gather experimental data. We were initially concerned that crowd-sourced participants (workers) would simply complete questionnaires in a random fashion in order to be paid. However, we found no evidence for this. "Gaming the system" by random scoring did not occur: participants correctly identified the personality trait we were portraying.

MT holds statistics on each worker, including acceptance rate. This is available to all requesters (those setting tasks) representing the percentage of work submitted by a particular worker that was approved (by all requesters). Thus if somebody consistently submits poor work, their acceptance rate drops. As requesters can set a high acceptance rate as a qualification for their tasks, this causes participants to value their acceptance 
rate, and complete tasks conscientiously. In addition to this, the integrated Cloze Test for English Fluency (Taylor 1953) was used as an attentional check to ensure participants were carefully reading the instructions, and had enough literacy skills to understand the task. We were also able to restrict participation to the United States only, which considerably drops the possibility of spam in the results.

The paper is structured as follows. Section 2 surveys the literature on measuring, conveying and adapting to personality. Section 3 describes the story creation process. Section 4 discusses the process of story validation. In Sect. 5, we test using the stories to measure user personality and outline how these results can be applied to group users by personality trait. Section 6 shows the application of the methodology by summarising many studies that investigated adaptation to personality and used the stories to convey or measure personality. Section 7 concludes the paper, discusses its limitations and provides directions for future work.

\section{Related work}

In this section, we describe the models of personality used in this paper and the rationale for choosing these, focusing specifically on trait theories and social learning approaches. We summarize the methods for obtaining users' personality traits and then summarize how personality can be portrayed, building on these methods. Finally, we discuss adaptation to personality in recommender systems, persuasive systems, and intelligent tutoring systems. We focus on adaptation to particular personality traits and the acquisition and portrayal of personality in the studies conducted.

\subsection{Models of personality}

\subsubsection{Personality trait theories}

Traits are defined as "an enduring personal characteristic that reveals itself in a particular pattern of behaviour in different situations" (Carlson et al. 2004, p. 583). Over time, trait theorists have tried to identify and categorise these traits (Carlson et al. 2004). The number of traits identified has varied, with competing theories arising. The best known include Eysenck's three factors (Eysenck 2013), Cattell's 16PF (Cattell 1957), and the Five-Factor Model (FFM) (Goldberg 1993). More recently a general consensus towards five main traits (or dimensions) (Digman 1990; McCrae and John 1992) has emerged, shown in Table 1 (reproduced from Digman 1990). Most psychologists consider the FFM robust (Magai and McFadden 1995), and a multi-year study found that individuals' trait levels remained relatively stable (Soldz and Vaillant 1999). The exact names of the traits are still disputed by psychologists (Goldberg 1993; McCrae and John 1992; Digman 1990), however we adopt the common nomenclature from John and Srivastava (1999) and refer to them as:

I Extraversion: How talkative, assertive and energetic a person is.

II Agreeableness: How good natured, cooperative and trustful a person is.

III Conscientiousness: How orderly, responsible and dependable a person is. 


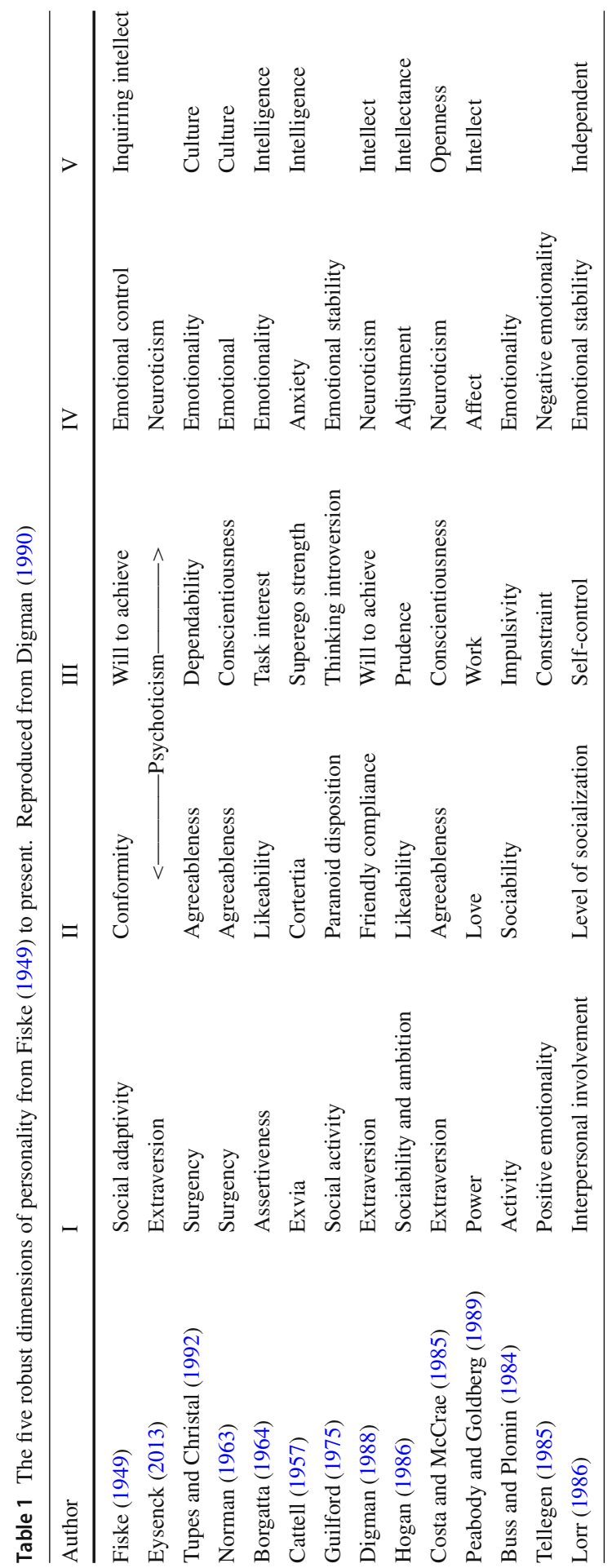


IV Emotional Stability (ES): How calm, non-neurotic and imperturable a person is. ${ }^{3}$

V Openness to Experience: How intellectual, imaginative and independent-minded a person is.

\subsubsection{Resilience}

The FFM is the core model of personality, as it is considered to be stable (i.e. a person's personality does not change, or changes very slowly). However, people also have traits that vary more quickly, encapsulate several core traits or are more environment/experience-dependent. One example is resilience, which is an often poorly defined term that encapsulates "the ability to bounce back from stress" (Smith et al. 2010, p. 166). Poor resilience is associated with depression (O'Rourke et al. 2010; Southwick and Charney 2012; Hjemdal et al. 2011) and anxiety (Connor and Davidson 2003; Hjemdal et al. 2011). While not as stable as the FFM traits, resilience is a medium-term trait that may be improved by interventions (Smith et al. 2010).

\subsubsection{Social learning approaches}

The Social Learning approach to personality "embodies the idea that both the consequences and behaviour and an individual's beliefs about those consequences determine personality" (Carlson et al. 2004, p. 593). Whereas trait theorists argue that knowing the stable characteristics of individuals can predict behaviour in certain situations; advocates of the Social Learning approach think that the environment surrounding an individual is more important when predicting behaviours (Carlson et al. 2004). Two popular Social Learning models are Locus of Control (Rotter 1966) (LoC) and (generalized) Self-Efficacy (Bandura 1994) (GSE).

An individual's Locus of Control represents the extent to which a person believes they can control events that affect them (Rotter 1966). A learner with an internal LoC believes that they can control their own fate, e.g. they feel responsible for the grades they achieve. A learner with external LoC believes that their fate is determined by external forces e.g. they believe that their grade is a result of the difficulty of the exam or their teaching quality. Self-Efficacy is defined as "the belief in one's capabilities to organize and execute the courses of action require to manage prospective situations" (Bandura 1995, p. 2) and determines whether individuals will adapt their behaviour to make changes in their environment, based on an evaluation of their competency (Carlson et al. 2004). It also defines whether an individual will maintain that change in behaviour in the face of adversity; GSE has been shown to be an excellent indicator of motivation (McQuiggan et al. 2008).

\subsection{Measuring personality}

There are many explicit or implicit approaches for measuring personality. Explicitly, personality traits can be obtained through self-reporting questionnaires, which

\footnotetext{
3 vs 'Neuroticism (N)'. Referring to this trait in this way is more consistent with the nomenclature of the other four traits (with higher scores inferring more "positive" personalities), and removes the need to invert this score's trait in analysis.
} 
typically ask users to rate to what extent certain statements apply to them. Multiple versions of such questionnaires exist - for example, the Five-Factor model (FFM) is often used in research, not only because there is broad agreement between psychologists, but because many validated questionnaires exist which measure it, with varying item numbers (e.g. 5 item FIPI (Gosling et al. 2003), 10 item TIPI (Gosling et al. 2003), BFI-10 (Rammstedt and John 2007), 20-item mini-IPIP (Donnellan et al. 2006), 40-item minimarkers (Saucier 1994a), 44-item BFI (John and Srivastava 1999), 50 item IPIP-NEO-50 (Goldberg et al. 2006), 60 item NEO-FFI (McCrae and Costa 2004), 240 item IPIP-PI-R, and 300-item IPIP-NEO Goldberg et al. 2006). Questionnaires for other traits also exist (see Table 2 for questionnaires that have been used for other traits). Advantages of measuring personality from self-reporting questionnaires include the ease of administration, the existence of validated questionnaires for most traits (so, easily extended to other traits), and transparency to users. Disadvantages are that they are often time consuming (leading to problems such as straight-lining Zhang and Conrad 2014) and may be inaccurate (either because respondents see themselves differently then they really are, or because they want to portray a certain image to other people).

Personality traits can be measured implicitly using machine learning techniques. Personality can be inferred from user generated content in social media, e.g. Facebook Likes (Kosinski et al. 2014; Youyou et al. 2015), language used (Park et al. 2015; Oberlander and Nowson 2006), Twitter user types (e.g. number of followers) (Quercia et al. 2011), a combination of linguistic and statistical features (e.g. puctuation, emoticons, retweets) (Celli and Rossi 2012), and structural social network properties (Bachrach et al. 2012; Quercia et al. 2012; Lepri et al. 2016). See Farnadi et al. (2016) for a comparative analysis.

Alternatively other interaction data can be used, such as measuring personality traits from gaming behaviour. For example, Cowley and Charles (2016) use features that describe game player behaviour based on the temperament theory of personality, Yee et al. (2011) measure personality from player behaviour in World of Warcraft, Wohn and Wash (2013) from spatial customisation in a city simulation game, and Koole et al. (2001) using a common resources dilemma gaming paradigm. Implicit association tests have also been used, measuring reaction times to visual stimuli associated with contrasting personality descriptors (Grumm and von Collani 2007).

Non-verbal data can also be used from speech and video, such as prosody, intonation, gaze behaviour, and gestures. For example, Polzehl (2014) details how speech features can be used. Biel and Gatica-Perez (2013) use features from video blogs such as speaking time, speaking speed, how much the person looks at the camera. Staiano et al. (2011) use speech and gaze attention features from videos of meetings. Rojas et al. (2011) use facial features.

Finally, multi modal personality recognition can also be used; for example Farnadi et al. (2014) used a combination of textual (linguistic and emotional) features extracted from transcripts of video blogs in addition to audio-video features. Similarly, Srivastava (2012) used a combination of non-verbal behaviour and lexical features.

For a more in depth review of automated personality recognition including a summary of existing studies and which personality traits were recognised see Vinciarelli and Mohammadi (2014). 
Table 2 Examples of existing work on adapting to personality

\begin{tabular}{|c|c|c|c|}
\hline References & Adapting & Personality traits & Personality measure \\
\hline \multicolumn{4}{|l|}{ Persuasive system } \\
\hline Kaptein et al. $(2012,2015)$ & Messages & $\begin{array}{l}\text { Susceptability to } \\
\text { Cialdini principles }\end{array}$ & $\begin{array}{l}\text { STPSKaptein et al. } \\
\text { (2012) }\end{array}$ \\
\hline Orji et al. (2014) & Strategies & Gamertypes & $\begin{array}{l}\text { BrainHex (Nacke } \\
\text { et al. 2014) }\end{array}$ \\
\hline Smith et al. (2016) & Reminders & FFM & Sliders (this paper) \\
\hline Schiavo et al. (2016) & Group participation & FFM & BFI-10 \\
\hline de Vries et al. (2016) & Change processes & FFM & IPIP-NEO \\
\hline Alkiş and Temizel (2015) & Strategies & & BFI \\
\hline Arteaga et al. (2010) & $\begin{array}{l}\text { Game choice and } \\
\text { messages }\end{array}$ & FFM & BFI-10 \\
\hline Halko and Kientz (2010) & Strategies & FFM & BFI \\
\hline Hirsh et al. (2012) & Phone adverts & FFM & $\begin{array}{l}\text { BFAS (DeYoung et al. } \\
\text { 2007) }\end{array}$ \\
\hline Lepri et al. (2016) & Social strategies & FFM & BFI \\
\hline Chen et al. (2015) & Travel adverts & FFM $(\mathrm{O}, \mathrm{ES})$ & $\begin{array}{l}\text { tweets; } 20 \text { from } \\
\text { IPIP-NEO-50 }\end{array}$ \\
\hline Nov and Arazy (2013) & Rating UI & FFM (C) & 2 from TIPI \\
\hline Orji et al. (2017) & Strategies & FFM & BFI-10 \\
\hline Oyibo et al. (2017) & Message type & FFM & TIPI \\
\hline $\begin{array}{l}\text { Anagnostopoulou et al. } \\
\text { (2017) }\end{array}$ & Strategies & FFM & BFI-10 \\
\hline de Vries et al. (2017) & Message type & FFM & IPIP-NEO-50 \\
\hline Nguyen et al. (2018) & Feedback,reminders & FFM & $\begin{array}{l}60 \text { item Truity LLC } \\
\text { (2018) }\end{array}$ \\
\hline Ciocarlan et al. (2017) & Challenges & FFM $(\mathrm{C}, \mathrm{O}, \mathrm{ES})$ & Portrayed \\
\hline Orji et al. (2018) & Strategies & Gamertypes & $\begin{array}{l}\text { Hexad (Tondello et al. } \\
\text { 2016) }\end{array}$ \\
\hline Ciocarlan et al. (2018) & Messages, Tasks & FFM & TIPI \\
\hline \multicolumn{4}{|l|}{ Intelligent tutoring system } \\
\hline Dennis et al. (2016) & Feedback & FFM & Portrayed \\
\hline Okpo et al. (2016b, 2017) & Exercise selection & Self-esteem & Portrayed \\
\hline Alhathli et al. (2016) & Material selection & FFM (E) & Portrayed \\
\hline Conati and Maclaren (2009) & Educational hints & FFM (C,E,A,ES) & $\begin{array}{l}\text { Personality test for } \\
\text { children Graziano } \\
\text { et al. (1997) }\end{array}$ \\
\hline Robison et al. (2010) & Feedback type & FFM & $\begin{array}{l}\text { NEO-PI-R Costa and } \\
\text { McCrae (2008) }\end{array}$ \\
\hline Harley et al. (2016) & Prompt, Feedback & FFM & mini-IPIP \\
\hline
\end{tabular}


Table 2 continued

\begin{tabular}{|c|c|c|c|}
\hline References & Adapting & Personality traits & Personality measure \\
\hline Leontidis et al. (2011) & Pedag. Strategy & FFM & IPIP-NEO \\
\hline Santos et al. (2016) & $\begin{array}{l}\text { Affective rec. for } \\
\text { language learning }\end{array}$ & FFM, GSE & $\begin{array}{l}\text { GSE (Schwarzer and } \\
\text { Jerusalem 1995), } \\
\text { BFI }\end{array}$ \\
\hline Santos et al. (2014) & Emotional support & FFM, GSE & GSE, BFI \\
\hline McQuiggan et al. (2008) & Feedback & GSE & GSE \\
\hline $\begin{array}{l}\text { Sarsam and Al-Samarraie } \\
\text { (2018) }\end{array}$ & Interface display & FFM & IPIP-NEO \\
\hline
\end{tabular}

\section{Recommender system}

$\mathrm{Hu}$ and $\mathrm{Pu}$ (2011)

Nov et al. (2013)

Cold-start rec.

FFM

TIPI

Tkalčič et al. (2011)

\section{Rating UI}

FFM (E,ES)

TIPI

Tintarev et al. (2013)

Cold-start rec.

FFM

IPIP-NEO-50

Chen et al. (2016)

Diversity

FFM (O)

Portrayed

Cantador et al. (2013)

Quijano-Sanchez et al. (2010)

Diversity

FFM

25 items

Cross-domain rec.

FFM

IPIP-NEO

Group rec.

Accommodating,

Competing,

Collaborating,

Compromising,

Avoiding

Kompan and Bieliková (2014)

Group rec.

FFM (E,N), Competing, Coop.

Rawlings and Ciancarelli (1997)

Ferwerda et al. (2015)

Appel et al. (2016)

Nunes (2008)

Braunhofer et al. (2015)

Odić et al. (2013)

Range of items, Popularity of items

FFM $(\mathrm{O}, \mathrm{E})$

TKI Thomas (2008)

Preferred choice for browsing

Recommendations

FFM (O,C,ES)

BFI

Closeness, Curiosity, Social media (Gou Adventurous et al. 2013)

Recommendations

FFM

IPIP-NEO

Recommendations

FFM

FIPI

Emotion Induction

FFM (A,E)

IPIP-NEO-50

(e.g. in group vs alone)

Fernández-Tobías et al. (2016)

Cold-start rec.

FFM

MyPersonality (Kosinski 2012)

Wu and Chen (2015)

Nguyen et al. (2017)

\section{and serendipity}

Recommendations $\quad$ FFM

Implicit, 25-items

Diversity, popularity, FFM

TIPI

Wu et al. (2018)

Diversity

FFM

BFI 
Advantages of measuring personality implicitly are that it can be done unobtrusively (as long as the data used is generated naturally) and tends to have good accuracy. Disadvantages are potential privacy implications (it is important that users provide explicit consent), the need for substantial data for the underlying machine learning algorithms (so it requires time to measure the personality of new users) and the poor availability of existing datasets for other applications. Dunn et al. (2009) investigated ease of use, user satisfaction, and accuracy for three interfaces to obtain personality, one explicit one (NEO PI-R, with 240 questions) and two implicit ones (a game and an implicit association test). They concluded that an explicit way of measuring personality is better for ease of use and satisfaction.

\subsection{Portraying personality}

Personality can be portrayed in many ways, often inspired by the ways in which it can be measured. Firstly, participants can be shown content generated by someone who with the personality trait we want to portray, such as a blog post, audio recording, or video. This is hard to do well, as it is difficult to avoid conveying information beyond personality. For example, facial expressions (as may be present in video recordings), speech (as present in video and audio recordings), and linguistic content (as present in text and speech) provide superfluous information about affective state (Zeng et al. 2009). Video, audio and text often also implicitly provide information about the person's ethnicity/region of origin, age, gender, and opinions (Rao and Yarowsky 2010). Additionally, it requires finding those with exactly the personality trait required, and obtaining their permission for using content they generate for this purpose.

Secondly, participants can be shown such content, but rather than using a person with a desired personality trait, the trait is portrayed by an actor, researcher or automatically generated based on what we know influences the measurement of certain personality traits. This provides more control, as an actor can be instructed to depict only one trait at the extreme, and to try to be neutral on other variables, such as affective state. Social Psychology and Medical Education commonly use actors to depict personality traits. For example, Kulik (1983) used actors to portray extraversion (actor smiled, spoke rapidly and loudly, discussed drama, reunions with friends, lively parties) and introversion (actor spoke more hesitantly, talked about his law major, lack of spare time, interest in Jazz). Barrows (1987) describes stimulated/standardized patients as presenting the gestalt of the patient being simulated including their personality. The problem remains that actors also provide information about gender, age, ethnicity. Additionally, hiring good actors may be costly.

Portraying personality is also widely investigated in the Affective Computing community, particularly by virtual agents (Calvo et al. 2015). For example, Doce et al. (2010) convey the personality of game characters by the nature and strengths of emotions a character portrays, and their tendency to act in a certain manner. However, this is still difficult to do well, and again it is hard to do it in a way that only a personality trait is expressed and nothing more.

Thirdly, a person can be described explicitly by mentioning the personality trait (e.g. "John is very conscientious") or how the person behaves or would behave in certain 
circumstances (e.g. "John tends to get his work done very rapidly"). For example, Luchins (1958) produced short stories to portray extraversion and introversion. These contained sentences such as "he stopped to chat with a school friend who was just coming out of the store" and "[he] waited quietly till the counterman caught his eye". Using a single sentence with just the personality trait is easy to do, but it may not provide participants with a strong enough perception of the trait and it can easily be overlooked. Using a story solves this, but the story may not convey the intended trait.

In all of these cases, it is important that the portrayal of a personality trait is validated as accurately creating the impression of personality intended, and not producing additional impressions (of an unintended personality trait or attribute such as intelligence, etc). For example, Luchins (1958) actually found that participants associated many other characteristics (such as friendliness) based on his stories. Kulik (1983) found that prior conceptions about the actors influenced people's opinions.

\subsection{Adapting to personality}

There is growing interest in personalization to personality, as seen from the UMUAI 2016 special issue on "Personality in Personalized Systems" (Tkalčič et al. 2016) and the "Emotions and Personality in Personalized Systems" (EMPIRE) workshops. Research on personalization to personality has focused mainly in three domains: Persuasive Technology, Intelligent Tutoring Systems, and Recommender Systems. Table 2 presents a non-exhaustive list of such research.

As shown in Table 2, research on personality in Persuasive Systems has mainly focused on adapting messages (motivational messages, prompts, adverts, reminders) and selecting persuasive strategies. Adaptation tends to use the Five Factor Model, though there has also been work on adapting to susceptibility to persuasion principles and gamer types. ${ }^{4}$ All papers cited use self-reporting questionnaires.

Research on personality in Intelligent Tutoring Systems has mainly focused on adapting feedback/emotional support, navigation (exercise and material selection) and hints/prompts. The Five Factor Model tends to be the basis for personality adaptation, though generalized self-efficacy (GSE) is also used. To assess personality, all papers cited used self-reporting questionnaires, except for Dennis et al. (2016), Okpo et al. (2016b) and Alhathli et al. (2016) who used indirect experiments in which participants made choices for a fictitious learner with a given personality.

Research on personality in Recommender Systems (see also Tkalčič and Chen 2015) has broadly considered the following topics: improving recommendation accuracy (Wu and Chen 2015), boot-strapping preferences for new users ( $\mathrm{Hu}$ and $\mathrm{Pu}$ 2011; Tkalčič et al. 2011; Fernández-Tobías et al. 2016), the impact of personality on users' preferences on recommendation diversity (Tintarev et al. 2013; Chen et al. 2016; Nguyen et al. 2017), cross-domain recommendation (Cantador et al. 2013), and group recommender systems (Kompan and Bieliková 2014; Quijano-Sanchez et al. 2010; Rawlings and Ciancarelli 1997). Adaptation in recommender systems aimed at individuals tends to use the FFM. However, for group recommender systems other

\footnotetext{
4 Based on the work by Perloff (2010), future work may include adapting to other personality traits such as self-monitoring, need for cognition, dogmatism and argumentativeness.
} 
Table 3 Self-report questionnaire for Generalized Self Efficacy (Schwarzer and Jerusalem 1995)

\begin{tabular}{ll}
\hline Statement & Score \\
\hline I can always manage to solve difficult & - \\
problems if I try hard enough & - \\
If someone opposes me, I can find the & \\
means and ways to get what I want & - \\
It is easy for me to stick to my aims & \\
and accomplish my goals & - \\
I am confident that I could deal effi- \\
ciently with unexpected events \\
Thanks to my resourcefulness, I know \\
how to handle unforeseen situations \\
I can solve most problems if I invest \\
the necessary effort \\
I can remain calm when facing dif- \\
ficulties because I can rely on my \\
coping abilities \\
When I am confronted with a problem, \\
I can usually find several solutions \\
If I am in trouble, I can usually think \\
of a solution \\
I can usually handle whatever comes \\
my way
\end{tabular}

Scoring: 1 = Not at all true, 2 = Hardly true, 3 = Moderately true, 4 = Exactly true

personality traits have been used (see also Masthoff 2015) such as cooperativeness. To assess personality all papers cited used self-reporting questionnaires, except Appel et al. (2016) who extracted personality from social media usage.

\section{Creation of stories to express personality traits}

This section describes the creation process of personality stories to express GSE, Resilience and the Five-Factor Model traits. ${ }^{5}$ These stories will be validated and amended in the next section. Male names were used for all stories to keep gender constant. If "gender neutral" names had been used, then participants' interpretation of the learner's sex may have caused an unwanted interaction effect on the validation.

\subsection{Stories for generalized self-efficacy}

The self-report questionnaire for Generalized Self Efficacy Schwarzer and Jerusalem (1995) was used as a starting point, shown in Table $3 .{ }^{6}$ Each questionnaire item is a

\footnotetext{
5 This is not an exhaustive list of traits, but a selection intended to convey the methodology, that we required for our other research.

${ }^{6}$ Reproduced here to clarify how the stories were created; please refer to the original paper Schwarzer and Jerusalem (1995) when using the questionnaire. 
Table 4 Stories used for Generalized Self-Efficacy, high and low

\begin{tabular}{l}
\hline Level \\
\hline Low \\
James is a first year student. When he is faced with a \\
difficult task, which requires him to solve a \\
problem which he has not seen before, he tends to \\
panic and give up, believing that he will never \\
solve the problem. He finds it difficult to defend \\
his ideas when someone disagrees with him. He \\
believes that he cannot solve problems by himself. \\
He finds it difficult to stick to his aims when \\
learning. He tends to be quite nervous, and doesn't \\
believe he can pass \\
James is a first year student. When he is faced with a \\
difficult task, which requires him to solve a \\
problem that he has not seen before, he remains \\
calm and believes he can always find a solution to \\
the problem, if he tries hard enough. He believes \\
he can defend his ideas if someone disagrees with \\
him. He believes that he can solve any problem, \\
whatever it is. He finds it easy to stick to his aims \\
when learning. He is laid back about his work and \\
believes that he will pass
\end{tabular}

positively weighted value. The overall score for GSE is the sum of each scale item, with a high score (max 40) indicating high GSE.

For the high GSE story, a selection of the questionnaire items were used and changed into the third person. For the low GSE story, the valence of the items was inverted. The stories were made more realistic by associating them with a character, a first year learner called "James" (the most popular male name in English in 2010, and therefore suitably generic). The resulting stories are shown in Table 4.

\subsection{Stories for resilience}

For Resilience, questions were used from the Connor-Davidson Resilience scale (Connor and Davidson 2003). These encapsulate 5 factors that contribute to resiliencePositive attitudes to change and strong relationships; Personal competency and tenacity; Spiritual beliefs and superstitions; Instincts and tolerance of negative emotions; and Control. Using questions from each factor, a story was composed for both high and low resilience (see Table 5) that are roughly symmetrical in order and content. The clauses 'David is kind and generous' (for both high and low stories) and 'He is friendly' (in the low story) were added to counter the fact that the low resilience story depicted a fairly negative character.

\subsection{Stories for the five factor model}

Unlike GSE and Resilience, the Five Factor Personality Trait Model does not describe a single trait. As discussed in Sect. 2.1.1, the five factors (traits) are Extraversion, 
Table 5 High and low resilience personality stories

\begin{tabular}{ll}
\hline Level & Story \\
\hline Low & $\begin{array}{c}\text { David is kind and generous. He is pessimistic and } \\
\text { dislikes challenges. He doesn't expect things to } \\
\text { get better when times are tough. He gives up } \\
\text { easily. He doesn't believe that doing good things } \\
\text { brings you good luck and thinks that events are } \\
\text { down to chance. He finds it hard to deal with } \\
\text { hardships and can't see the positive side of tricky } \\
\text { situations. He doesn't feel in control of his life. He } \\
\text { is friendly, but has few strong friendships. He is } \\
\text { modest of his achievements } \\
\text { David is kind and generous. He is optimistic and } \\
\text { likes challenges. He believes that when things go } \\
\text { badly, they will always get better and he will come } \\
\text { out stronger; whenever he fails, he tries harder } \\
\text { until he succeeds. He tries to do the right thing } \\
\text { because 'what goes around comes around'. He can } \\
\text { tough out hardships and make light of them. He } \\
\text { High } \\
\text { feels in control of his life. He has many close } \\
\text { friends and is proud of his successes }\end{array}$ \\
\hline
\end{tabular}

Table 6 Story construction for low emotional stability using the NEO-IPIP low items

NEO-IPIP Phrases

Generated story
"Often feel blue." "Dislike myself." "Am often down in the dumps." "Have frequent mood swings." "Panic easily." "Am filled with doubts about things." "Feel threatened easily." "Get stressed out easily." "Fear for the worst." "Worry about things"

"Josh often feels sad, and dislikes the way he is. He is often down in the dumps and suffers from frequent mood swings. He is often filled with doubts about things and is easily threatened. He gets stressed out easily, fearing the worst. He panics easily and worries about things"

Agreeableness, Conscientiousness, Emotional Stability and Openness to Experience. Thus, the personality of any individual can be described by five scores, one for each of the factors. This means that stories had to be created for each trait, at both low and high level (totalling 10 stories).

To make the FFM Stories, we used the NEO-IPIP 20-item scales (Gow et al. 2005): combining the phrases into sentences to form a short story, with the addition of a name picked from the most common male names. Unlike the GSE scale, these scales provided both positive and negative items, so the high and low story could be made from the positive and negative items respectively. Table 6 exemplifies how the stories were constructed. Table 7 shows the stories. 
Table 7 Preliminary Stories expressing each FFM trait at high and low levels

\section{Extraversion}

Low Jack has little to say to others, preferring to stay in the background. He would describe his life experiences as somewhat dull. He doesn't like drawing attention to himself, and doesn't talk a lot. He avoids contact with others and is hard to get to know. He retreats from others, finding it difficult to approach them. He keeps people at a distance

High Jack feels comfortable around people and makes friends easily. He is skilled in handling social situations, and is the life and soul of the party. He knows how to start conversations and easily captivates his audience. He warms up quickly to others, and likes talking to a lot of different people at parties. He doesn't mind being the centre of attention and cheers people up

Agreeableness

Low Charlie has a sharp tongue and cuts others to pieces. $\mathrm{He}$ suspects hidden motives in people. He holds grudges and gets back at others. He insults and contradicts people, believing he is better than them. He makes demands on others, and is out for his own personal gain

High Charlie has a good word for everyone, believing that they have good intentions. He respects others and accepts people as they are. He makes people feel at ease. He is concerned about others, and trusts what they say. He sympathizes with others' feelings, and treats everyone equally. He is easy to satisfy

\section{Conscientiousness}

Low Alexander procrastinates and wastes his time. He finds it difficult to get down to work. He does just enough work to get by and often doesn't see things through, leaving them unfinished. He shirks his duties and messes things up. He doesn't put his mind on the task at hand and needs a push to get started

High Alexander is always prepared. He gets tasks done right away, paying attention to detail. He makes plans and sticks to them and carries them out. He completes tasks successfully, doing things according to a plan. He is exacting in his work; he finishes what he starts

Emotional stability

Low Josh often feels sad, and dislikes the way he is. He is often down in the dumps and suffers from frequent mood swings. He is often filled with doubts about things and is easily threatened. He gets stressed out easily, fearing the worst. He panics easily and worries about things

High Josh seldom feels sad and is comfortable with himself. He rarely gets irritated, is not easily bothered by things and he is relaxed most of the time. He is not easily frustrated and seldom gets angry with himself. He remains calm under pressure and rarely loses his composure 
Table 7 continued

Openness to experience
Low
Oliver is not interested in abstract ideas, as he has
difficulty understanding them. He does not like art,
and dislikes going to art galleries. He avoids
philosophical discussions. He tends to vote for
conservative political candidates. He does not like
poetry and rarely looks for a deeper meaning in
things. He believes that too much tax money goes to
supporting artists. He is not interested in theoretical
discussions
Oliver believes in the importance of art and has a vivid
imagination. He tends to vote for liberal political
candidates. He likes to carry the conversation to a
higher level, enjoying hearing new ideas. He enjoys
thinking about things and can express himself
beautifully. He enjoys wild flights of fantasy, getting
excited by new ideas. He has a rich vocabulary

\section{Validation of stories to express personality traits}

This section describes the validation process of each story: how each story was checked that it correctly depicted the trait that it was intended to depict (the target trait).

A series of validation studies were performed for the stories constructed to convey Generalised Self-Efficacy, Resilience, and the traits from the FFM (Extraversion, Agreeableness, Conscientiousness, Emotional Stability and Openness to Experience). Each trait had two stories associated with it-one to express the trait at a high level, and one to express the trait at a low level.

For each trait, at least one validation experiment was conducted (the traits from the Five Factor Model required more, this is explained further in Sect. 4.3). Each validation experiment utilized a between-subjects design: participants were shown either the high story or the low story, and then asked to rate the personality of the person depicted in the story using a validated questionnaire for the trait in question.

As outlined in Sect. 3, the stories were originally constructed using an existing personality measurement questionnaire. For validation purposes, a different measurement questionnaire was used for the same trait, as this used different language and terms to the story (preventing participants from just recognising phrases), and made the purpose of the experiment less obvious and decrease demand characteristics.

For the GSE and FFM stories, we also measured how the stories conveyed other traits (non-target traits), to check how they were conveyed. For GSE, we investigated how the stories conveyed the FFM traits and Locus of Control. ${ }^{7}$ It has been shown previously (Judge et al. 2002; Hartman and Betz 2007) that GSE interacts with both of these measures, however, if we found an unexpected interaction this would allow us to correct the story. For the FFM stories we checked how the other four non-target FFM

\footnotetext{
7 This research was developed in the e-learning domain, where previous literature identified GSE, FFM and locus of control as salient adaptation characteristics. Therefore it would be desirable to have stories that isolated these traits, hence their inclusion.
} 
Table 8 Results of $t$ tests for GSE story validation

\begin{tabular}{|c|c|c|c|c|c|}
\hline \multirow[t]{2}{*}{ Trait } & \multicolumn{2}{|c|}{ Low GSE story } & \multicolumn{2}{|c|}{ High GSE story } & \multirow[t]{2}{*}{$p$} \\
\hline & Mean & SD & Mean & SD & \\
\hline $\mathrm{GSE}^{\mathrm{a}}$ & 15.42 & 4.18 & 32.13 & 4.56 & $<0.001$ \\
\hline Extraversion $^{\mathrm{b}}$ & 4.75 & 0.61 & 5.08 & 0.52 & $>0.05$ \\
\hline Agreeableness ${ }^{\mathrm{b}}$ & 4.63 & 0.89 & 4.79 & 0.58 & $>0.05$ \\
\hline Conscientiousness $^{\mathrm{b}}$ & 4.58 & 0.57 & 5.08 & 0.52 & $<0.05$ \\
\hline Emotional Stability & 4.93 & 0.73 & 4.71 & 0.97 & $>0.05$ \\
\hline Openness $^{\mathrm{b}}$ & 4.82 & 0.68 & 4.83 & 0.46 & $>0.05$ \\
\hline Locus of Control ${ }^{\mathrm{c}}$ & 8.92 & 2.76 & 2.67 & 2.28 & $<0.001$ \\
\hline
\end{tabular}

Bold values indicate significant difference between high and low story

${ }^{\text {a From }} 8$ to 40 with 8 lowest

${ }^{\mathrm{b}}$ From 1 to 9 with 1 lowest

${ }^{\mathrm{c}}$ From 0 to 13 with 0 indicating entirely internal locus and 13 indicating entirely external locus

traits were conveyed. ${ }^{8}$ For Resilience, which again used crowd sourcing, a different approach was taken, which is elaborated on in Sect. 4.2.

\subsection{Generalized self-efficacy (GSE) validation}

This experiment explored whether stories did correctly convey different levels of GSE, and what other personality traits were implied, using a different validated trait assessment questionnaire for GSE (Chen et al. 2001). We also explored how the story depicted other traits in the FFM (using minimarkers Saucier 1994a) and a questionnaire for Locus of control (Goolkasian 2009). Fifty participants (42\% female, $52 \%$ male, $6 \%$ preferred not to say; $34 \%$ aged $18-25,48 \%$ aged $26-40,14 \%$ aged $41-65,2 \%$ aged over $65,2 \%$ preferred not to say) recruited through convenience sampling in a betweensubject design, answered these questionnaires, after reading the GSE personality story. 26 viewed the low GSE story and 24 viewed the high GSE story.

Table 8 shows the results. $t$ tests ${ }^{9}$ were run for each of the traits to test whether the high and low GSE stories were significantly different from each other. This was significant at $t(48)=-13.514, p<0.001$. A Point-Biserial Correlation showed a

\footnotetext{
8 As explained later, these stories needed alterations, and therefore crowd-sourcing was used to recruit the much larger number of participants required. The use of crowd-sourcing meant that we no longer investigated how the FFM stories were rated on the GSE and LOC scales, as including these scales would make the experiments too cumbersome and time consuming for participants on this platform.

9 Throughout this paper we use parametric measures to analyse Likert data. The conventional way to analyse personality tests is to total or average the score for the questions that relate to each factor; this indicates that the developers of these validated questionnaires intend the Likert scale items to be treated as numerical items. Indeed, the analyses of these questionnaires are generally provided by the scale developer using parametric methods. Whether to use a Mann-Whitney or $t$ test on Likert data is debatable; Likert scales are commonly analysed using a $t$ test, though there is good reason to treat them as non-parametric data. However, in practical application it has been found that there is little to no difference in the outcome, especially in the likelihood of Type 1 error (De Winter and Dodou 2010).
} 
significant difference $\left(r(50)=0.89, p<0.001, R^{2}=0.79\right)$, showing a strong effect size for the GSE Stories.

The stories did however express some other personality traits and models at significantly different levels (Conscientiousness and Locus of control). However, this was to be expected as GSE is not an isolated construct: previous research has discussed possible correlations between GSE and other psychological constructs, including conscientiousness and locus of control (Judge et al. 2002; Hartman and Betz 2007). We therefore judged that these stories were sufficient for further experiments.

\subsection{Resilience validation}

Similarly to GSE, resilience is expected to correlate with other personality traits. We validated that the high and low stories depicted high and low resilience; no other traits were compared as it was anticipated that there would be an interaction (e.g. with low emotional stability) and this is not a problem for this measure. 44 participants were recruited through MT (26 female, 17 male, 1 undisclosed, aged 18-65). They were shown either the high or low story (between-subjects design) and asked them to assess the person in the story on the six item 'Brief Resilience Scale' (Smith et al. 2008). We added six items from another scale to mitigate hypothesis guessing and reduce response bias.

To validate the stories, we performed a between-subjects $t$ test to test Average Resilience rating between the low and high stories. This was significant at $t(41)=$ $0.29, p<0.001$. The mean resilience rating was $1.75 \pm 0.51 \mathrm{SD}$ for the low story and $4.20 \pm 0.49 \mathrm{SD}$ for the high story on a $1-5$ scale. A Point-Biserial Correlation showed a significant difference $\left(r(43)=0.93, p<0.001, R^{2}=0.85\right)$, showing a strong effect size for the Resilience Stories.

\subsection{Five factor trait validation}

This section is an improved version of previous research reported in Dennis et al. (2012b), with clarifications and an additional effect size analysis.

\subsubsection{First iteration FFM: pilot study}

The Emotional Stability stories from the FFM were used for a validation pilot study for the FFM traits, and to determine whether non-target trait mitigation would be required.

The same methodology from Sect. 4.1 was used. Eight participants (4 female; 5 aged 18-25, 3 aged 26-40) recruited through convenience sampling (4 students and 4 staff at the University of Aberdeen) were presented with one of the stories using a between-subjects design and asked to judge them on personality. However, as this was a pilot study, instead of using the 40 item minimarkers to judge the FFM, we used a TIPI questionnaire (Gosling et al. 2003) with 10 items instead (for brevity), shown in Fig. 2. The results are shown in Table 9.

The stories did convey Emotional Stability at polarized levels (i.e. the ratings for each story were at opposite ends of the scale for ES). However, there appeared to 


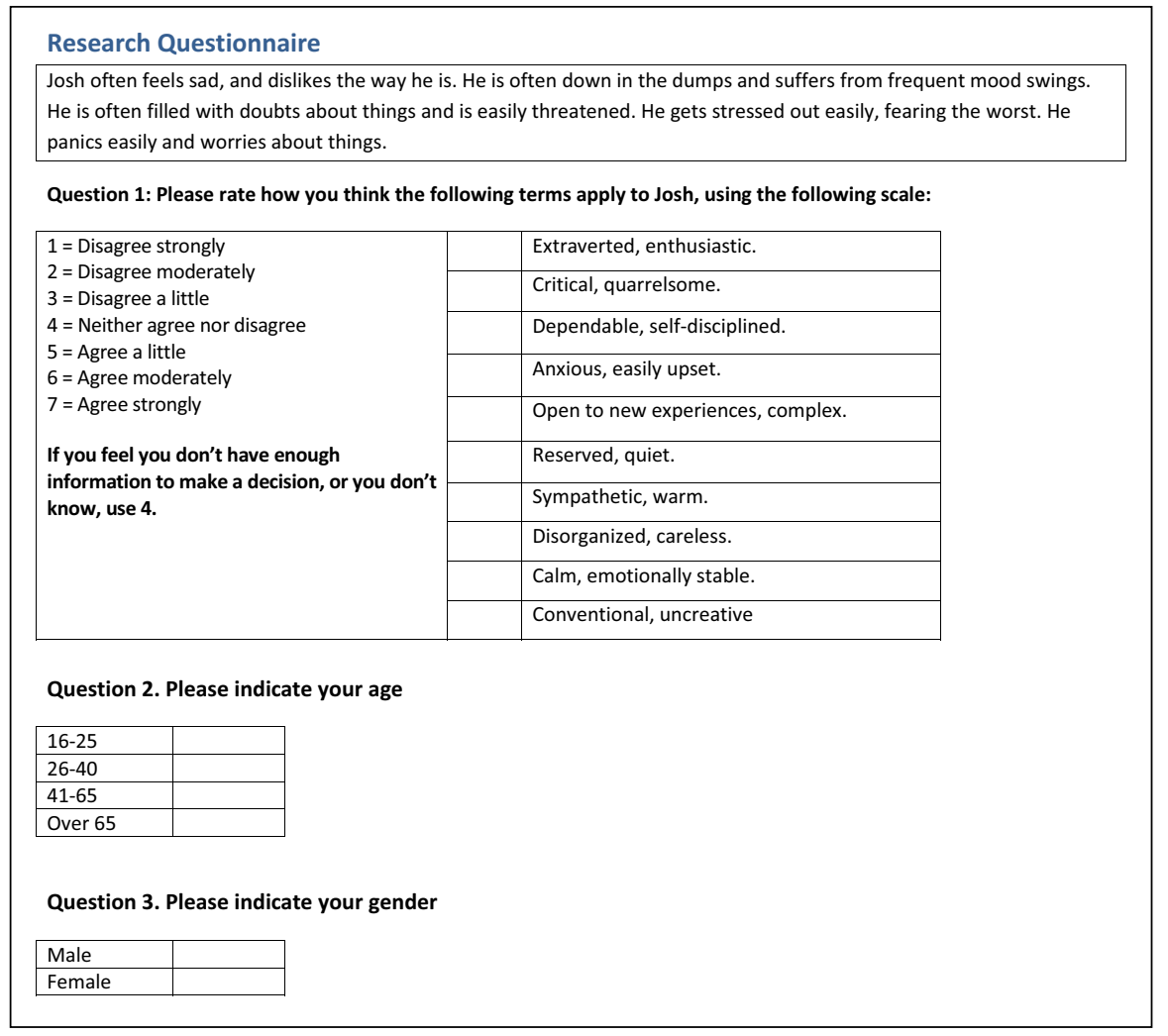

Fig. 2 The pilot story validation questionnaire, for Emotional Stability

Table 9 Results of pilot study for ES stories (high and low), as rated using TIPI for the FFM traits

\begin{tabular}{lcccccc}
\hline \multirow{2}{*}{ Trait } & \multicolumn{2}{l}{ Low ES story } & & \multicolumn{2}{l}{ High ES story } & $p$ \\
\cline { 2 - 3 } & Mean & SD & & mean & SD & $(t$ test $)$ \\
\hline Extraversion & 2.37 & 0.63 & & 3.75 & 1.26 & 0.10 \\
Agreeableness & $\mathbf{2 . 7 5}$ & 0.96 & & $\mathbf{5 . 1 3}$ & 0.25 & $\mathbf{0 . 0 1}$ \\
Conscientiousness & 2.75 & 1.26 & & 4.12 & 1.55 & 0.22 \\
Emotional Stability & $\mathbf{1 . 2 5}$ & 0.29 & & $\mathbf{5 . 7 5}$ & 1.32 & $<\mathbf{0 . 0 1}$ \\
Openness & 4.00 & 0.41 & & 3.88 & 0.63 & 0.75 \\
\hline
\end{tabular}

Values could range between 1 and 7. Bold values indicate significant difference between high and low stories. Grey cells indicate trait designed to convey

be a positive correlation with Agreeableness-more emotionally stable people were judged to be more agreeable (nicer) than neurotic ones. This effect could be spurious due to the low number of participants, or due to our decision to use the ten-item TIPI test rather than a more comprehensive test with a higher number of items. For more formal validation, a large number of unique participants is required for reliable data, particularly if adjustments to the stories are required. The second iteration uses 
Table 10 Normative ranges for each of the five traits, arising from the ratings of a liked peer for the minimarkers scale (Saucier 1994b), plus or minus one standard deviation

\begin{tabular}{llllll}
\hline Trait & $\mathrm{E}$ & $\mathrm{A}$ & $\mathrm{C}$ & $\mathrm{ES}$ & $\mathrm{O}$ \\
\hline Normative range & $4.75-7.63$ & $5.10-7.96$ & $4.48-7.10$ & $3.72-6.08$ & $4.99-7.45$ \\
\hline
\end{tabular}

a larger set of participants recruited through crowd-sourcing to establish whether the correlation with Agreeableness persists and also attempts to validate the stories for the other FFM traits.

\subsubsection{Second iteration: validation of stories for the five factor model}

100 participants (10 per story; 67\% female) were recruited using MT. In a betweensubjects design, each participant was presented with one story about a learner (see Table 7) which attempted to convey a target trait at either a high or low-level. Participants assessed this student's personality using the Mini-Markers scale (Saucier 1994a).

The rating for the target trait (i.e. the trait that the story was created to express) should be as polarized as possible - the "low" variant of a story aimed for a score as close to 1 as possible, and the "high" story aimed for a score as close to 9 as possible.

The decision for an acceptable value for a non-target trait is rather arbitrary. However, it is possible to derive normative values for each trait from large population samples. As these samples are similar to our own (e.g. English-speaking, USA-based), we decided it was acceptable to use these to characterise people as being either 'high', 'low' or 'neutral' in a trait.

To decide on acceptable values for non-target traits, a "normative range" was made for each of the five traits based on the average ratings of a liked peer for the minimarkers scales from 329 students from Illinois (Saucier 1994b), ${ }^{10}$ plus or minus one standard deviation, shown in Table 10.

Results Table 11 shows the results of the original stories. There was a significant difference between all 5 pairs of stories in the perceived trait values for the target trait between the high story and the low story. For all but one personality trait (Openness), the perceived target trait values were clearly outside the normative range and in the correct direction. The perceived target trait value for low openness is below the normative range, but high story marginally outside the normative range. Problematically, there were many significant differences between the perceived non target trait values. Several perceived non-target trait values were also outside the normative range.

\footnotetext{
10 The 'liked peer' data was used as it was closer to the task in our experiment i.e. rating the personality of another person. A retrospective comparison of the self-reported minimarker scores of a subset of MTurk users revealed that the means for each trait are within 1SD of the means for the Illinois population, except for Emotional Stability, where the mean in the MTurk group was higher (6.29 vs 4.90). This is sufficiently similar to make the populations comparable.
} 
Table 11 Results for FFM stories

\begin{tabular}{|c|c|c|c|c|c|c|}
\hline \multicolumn{2}{|c|}{ Story } & \multicolumn{5}{|c|}{ Perceived trait levels } \\
\hline Trait & Level & $\mathrm{E}$ & A & $\mathrm{C}$ & ES & $\mathrm{O}$ \\
\hline \multirow{2}{*}{$\mathrm{E}$} & Low & $1.78(0.76)$ & $4.85(1.31)$ & $6.08(1.04)$ & $4.90(0.52)$ & $5.47(1.35)$ \\
\hline & High & $8.25(0.42)$ & $7.47(0.62)$ & $5.52(1.04)$ & $6.10(0.85)$ & $5.77(0.65)$ \\
\hline \multirow{2}{*}{ A } & Low & $7.10(0.73)$ & $1.71(0.88)$ & $4.91(0.57)$ & $2.80(1.01)$ & $4.96(0.77)$ \\
\hline & High & $6.37(0.88)$ & $8.48(0.49)$ & $5.67(0.96)$ & $7.28(0.96)$ & $5.20(0.50)$ \\
\hline \multirow{2}{*}{$\mathrm{C}$} & Low & $4.79(0.45)$ & $4.75(0.45)$ & $2.00(0.76)$ & $4.93(0.37)$ & $3.44(1.14)$ \\
\hline & High & $5.73(0.57)$ & $6.30(1.06)$ & $8.13(0.98)$ & $5.73(0.89)$ & $5.30(1.13)$ \\
\hline \multirow{2}{*}{ ES } & Low & $3.92(0.76)$ & $5.05(0.37)$ & $4.25(0.94)$ & $3.07(0.47)$ & $5.23(1.14)$ \\
\hline & High & $5.96(1.08)$ & $6.57(0.83)$ & $6.64(1.34)$ & $7.73(0.94)$ & $5.44(0.70)$ \\
\hline \multirow{2}{*}{$\mathrm{O}$} & Low & $4.70(0.92)$ & $3.92(1.42)$ & $6.22(0.97)$ & $4.76(1.35)$ & $2.76(1.54)$ \\
\hline & High & $7.75(0.82)$ & $5.67(1.11)$ & $5.43(1.20)$ & $5.67(1.22)$ & $7.48(1.61)$ \\
\hline
\end{tabular}

Bold items indicate $p<0.05$, ( $t$ test Bonferroni corrected) between low/high stories. Grey cells indicate target trait levels. Italics indicate non-target trait outside normative range. Target trait score underline-score not outside normative range

\subsubsection{Mitigation}

The following problems occurred between the pairs of stories during validation:

P1: Perceived trait values on a non-target trait differ significantly

$\mathrm{P} 2$ : Perceived trait values on a non-target trait are outside the normative range

P3: Perceived target trait values are very close to normative range

Problems P1 and P2 often appeared together-one (or both) of the perceived values for a non-target trait were outside the normative range and thus significantly different from the other. For example, in the story for low extraversion, the student was perceived to be less agreeable, despite correctly conveying low extraversion and the scores for the remaining non target traits being within the normative range. We hypothesised that the following story modifications could be taken in an attempt to mitigate problems $\mathrm{P} 1$ and P2:

S1: Add a statement which implies a semi neutral stance on the problem trait, e.g. "Jack is quite a nice person" to mitigate low agreeableness.

S2: Remove a statement which may be causing the interaction-e.g. removing "Jack has little to say to others" may increase agreeableness.

S3: Add a statement targeting the problematic non-target trait from its own storye.g. adding "Jack has a good word for everyone" from the high agreeableness story to increase agreeableness in other stories.

S1 was used because S2 (removing statements from the stories) was undesirable: this may affect the story's expression of the target trait. We did not attempt S3 as it may over-alter the non-target trait score, and introducing another trait into a story may bring that trait's undesirable interactions into the story. For example, the low conscientiousness story also conveys low agreeableness (see Table 16). If we added a statement from the high agreeableness story, this could in turn raise the ES 
Table 12 Mitigating Statements for each non-target FFM trait

\begin{tabular}{ll}
\hline Non-target trait & Statement to add if below normative \\
\hline Extraversion & Tends to enjoy talking with people \\
Agreeableness & Quite a nice person \\
Conscientiousness & Tends to do his work \\
Emotional stability & Tends be calm \\
Openness & Quite likes exploring new ideas \\
\hline
\end{tabular}

Table 13 Two stories for high Openness to Experience
Original story

Modified story

Oliver believes in the importance of
art and has a vivid imagination. He
tends to vote for liberal political
candidates. He likes to carry the
conversation to a higher level,
enjoying hearing new ideas. He
enjoys thinking about things and
can express himself beautifully. He
enjoys wild flights of fantasy,
getting excited by new ideas. He
has a rich vocabulary
Oliver believes in the importance of
art and has a vivid imagination. He
tends to vote for liberal political
candidates. He enjoys hearing new
ideas and thinking about things. He
enjoys wild flights of fantasy,
getting excited by new ideas

Oliver believes in the importance of tends to vote for liberal political candidates. He likes to carry the conversation to a higher level, enjoying hearing new ideas. He njoys thinking about things and can express himself beautifully. He njoys wild flights of fantasy, getting excited by new ideas. He art and has a vivid imagination. $\mathrm{He}$ tends to vote for liberal political candidates. He enjoys hearing new enjoys wild flights of fantasy,

score, as the high agreeableness story also conveyed high ES (further confounding the problem).

\subsubsection{Third iteration: validation with mitigated sentences}

As the undesired non-target trait scores occurred most frequently in the low stories, these were targeted first. We constructed slightly positive statements (see Table 12) and added them where necessary. For the 'high' stories, only two non-target traits required modification: Extraversion in the Openness High story, and Emotional Stability in the Extraversion High and Agreeableness High stories. For the Extraversion High story, the score for Emotional Stability was 6.10, and the normative range ends at 6.08. Because this margin was so small, and there was no significant difference between the high and low variants' ES scores, modification was not attempted to avoid more adverse effects. In the case of the high Agreeableness story, the value for ES was 7.28. S1 was employed by adding a mildly negative statement: "He is occasionally a bit anxious". The Openness High story did not convey its target trait convincingly, and thus already required modification. Approach S2 was used in this case, removing statements such as "[he can] express himself beautifully" (see Table 13). 
Table 14 Point-Biserial correlations between the high and low story for each trait

\begin{tabular}{llll}
\hline Trait & $r$ & $R^{2}$ & $p$ \\
\hline Agreeableness & 0.95 & 0.90 & $<0.001$ \\
Extraversion & 0.99 & 0.97 & $<0.001$ \\
Openness to Experience & 0.87 & 0.76 & $<0.001$ \\
Conscientiousness & 0.98 & 0.95 & $<0.001$ \\
Emotional stability & 0.95 & 0.89 & $<0.001$ \\
\hline
\end{tabular}

Design The design was the same as Sect. 4.3.2. Seventy participants (10 per adjusted story) were recruited from MT. Each participant saw one story in a between-subjects design.

Results Tables 14 and 15 shows the results for the modified stories. S1 was successful in most cases in mitigating P1 and P2. Exceptions to this were in the Agreeableness stories, the undesired non-target trait scores still remain, with the Low story expressing low ES and the High story expressing high ES (P1 and P2). For Conscientiousness, $\mathrm{P} 1$ occurred for Openness, despite both values being in the normative range. For low Emotional Stability, S1 was not effective for bringing the perceived trait value into normative range for Extraversion, with P1 and P2 still extant. S2 was successful in solving P2 for Openness High; bringing the Agreeableness value into the normative range. However, we were not successful in solving P3 for Openness high; the score for the target trait is further within the normative range.

Effect Size for Modified Stories To explore how strongly the high and low stories differed for each trait, a Point-Biserial correlation was computed between the high and low stories for each trait. There was a strong positive correlation between the story trait level (low or high) and trait score for each trait, showing that the stories depict the traits strongly at the intended levels (see Table 14).

\subsubsection{Discussion}

The adjusted FFM stories are shown in Table 16. A story expressing a single polarized trait was always going to be difficult to achieve as the traits within the FFM are intercorrelated (Chamorro-Premuzic 2011). The interaction between Agreeableness and Emotional Stability was too strong to remove entirely. Adding a stronger statement to bring Emotional Stability into the normal range may cause more interactions with the other three non-target traits. In the Conscientiousness and Extraversion stories - the score for certain non target traits ( $\mathrm{O}$ and $\mathrm{A}$, respectively) still significantly differed. However, as these were all in the normal range, we do not see this as a problem. Problem P3 was not solved in the case of High Openness. Openness is a difficult trait to conceptualise-incorporating culture and art as well as political beliefs (Chamorro-Premuzic 2011). The perceived score was high, so it is likely therefore that it was expressing Openness highly, just not outside the range we devised. 
Table 15 Results for corrected FFM stories

\begin{tabular}{|c|c|c|c|c|c|c|}
\hline \multicolumn{2}{|c|}{ Story } & \multicolumn{5}{|c|}{ Perceived trait levels } \\
\hline Trait & Level & $\mathrm{E}$ & A & $\mathrm{C}$ & ES & $\mathrm{O}$ \\
\hline \multirow{2}{*}{$\mathrm{E}$} & Low & $2.00(0.64)$ & $5.91(1.04)$ & $5.64(0.88)$ & $5.05(1.00)$ & $5.48(1.18)$ \\
\hline & High $^{\mathrm{a}}$ & $8.25(0.42)$ & $7.47(0.62)$ & $5.52(1.04)$ & $6.10(0.85)$ & $5.77(0.65)$ \\
\hline \multirow{2}{*}{ A } & Low & $6.65(1.08)$ & $1.78(0.77)$ & $5.01(1.43)$ & $2.94(1.45)$ & $5.11(1.10)$ \\
\hline & High & $5.84(1.07)$ & $8.21(0.62)$ & $5.64(0.68)$ & $6.26(1.17)$ & $5.21(0.69)$ \\
\hline \multirow{2}{*}{$\mathrm{C}$} & Low & $6.59(0.69)$ & $5.93(0.86)$ & $2.16(0.91)$ & $5.67(1.01)$ & $5.06(1.03)$ \\
\hline & High $^{\mathrm{a}}$ & $5.73(0.57)$ & $6.30(1.06)$ & $8.13(0.98)$ & $5.73(0.89)$ & $5.30(1.13)$ \\
\hline \multirow{2}{*}{ ES } & Low & $4.49(1.59)$ & $6.38(0.67)$ & $5.77(1.00)$ & $3.35(0.71)$ & $5.97(0.76)$ \\
\hline & High $^{\mathrm{a}}$ & $5.96(1.08)$ & $6.57(0.83)$ & $6.64(1.34)$ & $7.73(0.94)$ & $5.44(0.70)$ \\
\hline \multirow{2}{*}{$\mathrm{O}$} & Low & $6.39(0.78)$ & $5.77(1.13)$ & $5.59(0.91)$ & $5.38(0.99)$ & $2.91(1.44)$ \\
\hline & High & $6.89(1.04)$ & $6.60(1.18)$ & $5.00(1.32)$ & $5.92(1.24)$ & $7.28(0.93)$ \\
\hline
\end{tabular}

Bold items indicate $p<0.05$, ( $t$ test Bonferroni corrected) between low/high stories. Grey cells indicate target trait levels. Italics indicate non-target trait outside normative range. Target trait score underline-score not outside normal range

${ }^{\text {a }}$ Story not adjusted, previous values used

Table 16 Validated stories for each FFM trait, high and low
Extraversion

Low Jack has little to say to others, preferring to stay in the background. He would describe his life experiences as somewhat dull. He doesn't like drawing attention to himself, and doesn't talk a lot. He avoids contact with others and is hard to get to know. He retreats from others, finding it difficult to approach them. He keeps people at a distance. Jack is quite a nice person

High Jack feels comfortable around people and makes friends easily. He is skilled in handling social situations, and is the life and soul of the party. He knows how to start conversations and easily captivates his audience. He warms up quickly to others, and likes talking to a lot of different people at parties. He doesn't mind being the centre of attention and cheers people up. Jack can sometimes be insensitive

Agreeableness

Low Charlie has a sharp tongue and cuts others to pieces. $\mathrm{He}$ suspects hidden motives in people. He holds grudges and gets back at others. He insults and contradicts people, believing he is better than them. He makes demands on others, and is out for his own personal gain. Charlie tends to be calm and quite likes exploring new ideas 
Table 16 continued

High Charlie has a good word for everyone, believing that
they have good intentions. He respects others and
accepts people as they are. He makes people feel at
ease. He is concerned about others, and trusts what
they say. He sympathizes with others' feelings, and
treats everyone equally. He is easy to satisfy. Charlie
tends to be quite anxious

Conscientiousness

Low Josh procrastinates and wastes his time. He finds it difficult to get down to work. He does just enough work to get by and often doesn't see things through, leaving them unfinished. He shirks his duties and messes things up. He doesn't put his mind on the task at hand and needs a push to get started. Josh tends to enjoy talking with people

High Josh is always prepared. He gets tasks done right away, paying attention to detail. He makes plans and sticks to them and carries them out. He completes tasks successfully, doing things according to a plan. He is exacting in his work; he finishes what he starts. Josh is quite a nice person, tends to enjoy talking with people, and quite likes exploring new ideas

\section{Emotional stability}

Low James often feels sad, and dislikes the way he is. He is often down in the dumps and suffers from frequent mood swings. He is often filled with doubts about things and is easily threatened. He gets stressed out easily, fearing the worst. He panics easily and worries about things. James is quite a nice person who tends to enjoy talking with people and tends to do his work

High James seldom feels sad and is comfortable with himself. He rarely gets irritated, is not easily bothered by things and he is relaxed most of the time. He is not easily frustrated and seldom gets angry with himself. He remains calm under pressure and rarely loses his composure

Openness to experience

Low Oliver is not interested in abstract ideas, as he has difficulty understanding them. He does not like art, and dislikes going to art galleries. He avoids philosophical discussions. He tends to vote for conservative political candidates. He does not like poetry and rarely looks for a deeper meaning in things. He believes that too much tax money goes to supporting artists. He is not interested in theoretical discussions. Oliver is quite a nice person, and tends to enjoy talking with people

High Oliver believes in the importance of art and has a vivid imagination. He tends to vote for liberal political candidates. He enjoys hearing new ideas and thinking about things. He enjoys wild flights of fantasy, getting excited by new ideas 


\subsection{Conclusion and limitations}

A set of stories for the FFM, GSE and Resilience have been constructed and validated. Not all FFM stories are perfect, modifying them seemed to "dilute" the effect of the target trait, implying a balancing act. Further strategies could be used to remove the remaining interactions, however it may be that one trait inevitably infers another. We judge that the stories are good enough at expressing the traits for the purpose of investigating adaptation to personality in intelligent systems.

\section{Using stories to determine personality}

In this section we investigate how to use the stories to measure personality. Participants were given a standardised personality test and asked to rate how close they were to a pair of diametrically opposed personality stories using a sliding scale. A correlational analysis was performed on each trait to show that the sliding scale measured the trait with a strong correlation coefficient. We then conducted a reliability check, where a new sample of participants completed the sliders twice, 1 week apart. The scores between week 0 and week 1 were strongly correlated - thus the sliders could be used to measure personality (though this should not replace a standardised test when high granularity is required).

\subsection{Methods}

\subsubsection{Materials}

The validated stories were taken from Tables 4, 5 and 16. Different common Western names were used for each story, gender-matched to the participant. These were formatted so that opposing stories of the same trait were placed at either end of a sliding scale (see Fig. 3). The scale was coloured using a gradient from blue to green (left to right), with markers every $12.5 \%$. The participant could indicate their position on the scale using a drag-and-drop slider. The position of the positive and negative stories was randomised for each participant and for each trait. The slider position gave a value of between 18 and 162, emulating a conventional 1-9 scale with greater acuity.

Validated personality questionnaires were used. For the Five Factor Model, the minimarker test (Saucier 1994a) was used. For resilience, the Brief Resilience Scale was used (Smith et al. 2008). For self-efficacy, the general self-efficacy scale was used (Schwarzer and Jerusalem 1995).

\subsubsection{Procedure}

Participants completed a personality questionnaire and then were presented with the slider test for each trait of the personality questionnaire they had completed, one at a time (five pairs of sliders for the Big Five Minimarker questionnaire and one pair 
Josh procrastinates and wastes

his time. He finds it difficult to get

down to work. He does just

enough work to get by and often

doesn't see things through,

leaving them unfinished. $\mathrm{He}$

shirks his duties and messes

things up. He doesn't put his

mind on the task at hand and

needs a push to get started.

Josh tends to enjoy talking with

people.

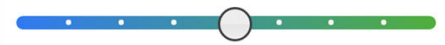

Fig. 3 Screenshot of the slider between opposing trait stories
James is always prepared. $\mathrm{He}$

gets tasks done right away,

paying attention to detail. He

makes plans and sticks to them

and carries them out. He

completes tasks successfully,

doing things according to a plan.

He is exacting in his work; he

finishes what he starts. Josh is

quite a nice person, tends to

enjoy talking with people, and

quite likes exploring new ideas.

Table 17 Participant demographics for FFM, Self Efficacy and Resilience for slider validation studies

\begin{tabular}{|c|c|c|c|c|c|c|c|c|c|}
\hline \multirow[t]{2}{*}{ Story set } & \multicolumn{5}{|l|}{ Age } & \multicolumn{3}{|c|}{ Gender } & \multirow[t]{2}{*}{ Total } \\
\hline & $18-25$ & $26-40$ & $41-65$ & Over 65 & n.d. & $\mathrm{F}$ & M & Other & \\
\hline FFM & 14 & 33 & 13 & 1 & 0 & 29 & 32 & 0 & 61 \\
\hline Self Efficacy & 10 & 33 & 18 & 1 & 0 & 25 & 37 & 0 & 62 \\
\hline Resilience & 13 & 31 & 15 & 1 & 0 & 19 & 41 & 0 & 60 \\
\hline
\end{tabular}

of sliders for each other questionnaire). ${ }^{11}$ Participants were asked to move the slider towards the person they thought they were most like. The slider was initially set at the $50 \%$ marker on the scale and participants had to manipulate the slider before they were allowed to continue, even if they chose to select 50\%. Participants were then thanked for their time and invited to view the results of the slider test in the form of a bar graph. Participants were recruited from MT and were paid \$0.80 (demographics shown in Table 17).

\subsubsection{Design}

Participants completed both the personality questionnaire and the slider test in a withinsubjects design. Their score on the personality questionnaire was the independent variable and the Value of the slider position (which represents how close to the 2 trait stories the participant thought they were) was the dependent variable.

Our hypothesis (H1) was: For each trait, there will be a positive correlation between personality score and slider value.

\subsection{Results}

\subsubsection{Five factor model}

For each trait, a correlation analysis was run of Trait Score $\times$ Slider Value. This was significant for each trait (see Table 18). Correlation graphs were plotted for each

\footnotetext{
11 The Minimarker scale was done first, to reduce the risk of straight-lining due to tiredness. There may have been a slight order effect, however as personality is relatively stable we do not expect an impact, particularly given the stories were not constructed from the Minimarker scale.
} 
Table 18 Pearson's $r$ for correlation of Trait Score $\times$ Slider Value for each personality trait, effect size $R^{2}$, regression formula and standardized error of the estimate $S E E$

\begin{tabular}{lllllll}
\hline Trait & $r$ & $R^{2}$ & $p$ & $n$ & Regression formula for slider & $S E E$ \\
\hline Conscientiousness & 0.69 & 0.48 & $<0.01$ & 61 & $2.23 \times$ ConScore -0.22 & 23.46 \\
Extraversion & 0.82 & 0.67 & $<0.01$ & 61 & $2.71 \times$ ExtScore -23.56 & 25.90 \\
Openness to Experience & 0.44 & 0.19 & $<0.01$ & 61 & $1.58 \times$ OpExScore +33.39 & 37.19 \\
Agreeableness & 0.64 & 0.41 & $<0.01$ & 61 & $1.67 \times$ AgrScore +29.48 & 21.60 \\
Emotional Stability & 0.46 & 0.21 & $<0.01$ & 61 & $1.67 \times$ EmStScore +27.16 & 32.64 \\
Resilience & 0.58 & 0.37 & $<0.01$ & 60 & $3.39 \times$ ResScore +43.25 & 25.53 \\
GSE & 0.62 & 0.38 & $<0.01$ & 62 & $3.33 \times$ GseScore +26.54 & 19.93 \\
\hline
\end{tabular}

trait (Fig. 4) and a regression analysis run. The regression formula for each trait is shown in Table 18. Participants' mean scores on the minimarkers scale (see Table 19) were compared with the minimarkers normal range (see Table 10) to see if the MT participants' varied from a normal population. All traits were within the normal range, except emotional stability which was slightly higher. To investigate the effect of other traits on the correlation for each trait, a partial correlation analysis was run to control for the effect of non-target traits. This correlations remain strong (see Table 20).

\subsubsection{Resilience and generalised self efficacy}

For each personality test, correlation graphs were plotted (Fig. 5) and a correlation analysis was run of Test Score $\times$ Slider Value. This was significant for Resilience $(r(60)=0.58, p<0.01)$ and GSE $(r(62)=0.62, p<0.01)$. The regression formula for each trait is shown in Table 18.

\subsection{Reliability check}

To test the reliability of the sliders, a reliability check experiment was conducted using all 7 sliders (FFM, GSE and Resilience). Participants recruited through opportunistic sampling completed the sliders and the FFM TIPI test (Gosling et al. 2003) as the first part of a persuasion experiment (reported in Ciocarlan et al. 2019). After 1 week they completed the sliders and TIPI test again (as well as the second part of the persuasion experiment).

Fifty-one participants completed the study (27 female, 23 male, 1 undisclosed; 21 aged 18-25, 23 aged 26-40, 7 aged 40-65). A correlation analysis was run between Slider Values for Week $0 \times$ Week 1 for all traits. The results are shown in Table 21 . There was a strong correlation for each of the sliders between Week 0 and Week 1 ( $r=$ $0.70-0.86$, mean $=0.81$ ). There were several other significant weaker correlationsexpected correlations between FFM traits and GSE and Resilience (as these traits are known to correlate with FFM traits; see Section 4), and some correlation within FFM traits. 


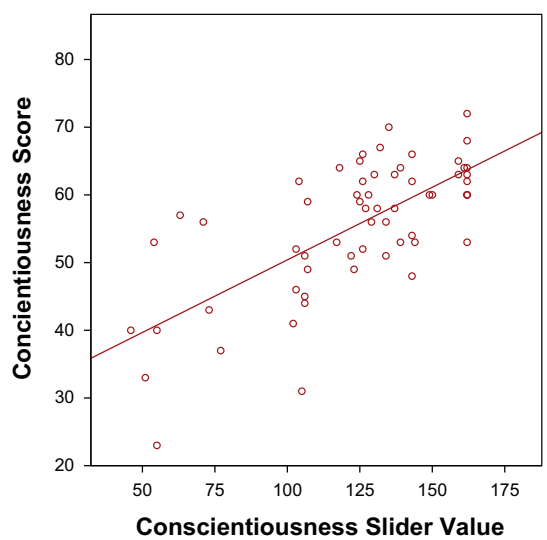

(a) Concientiousness

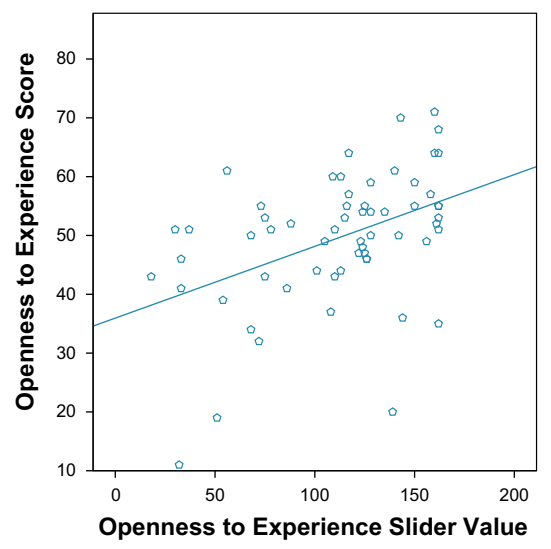

(c) Openness to Experience

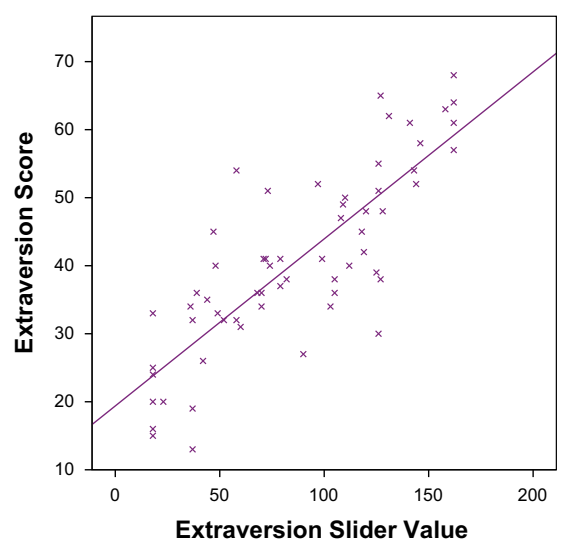

(b) Extraversion

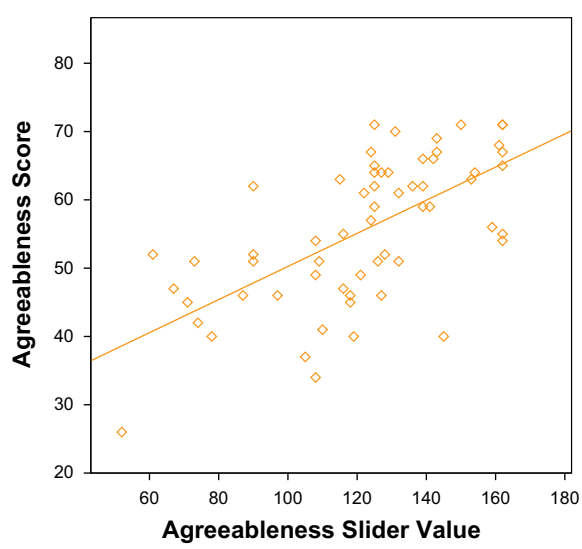

(d) Agreeableness

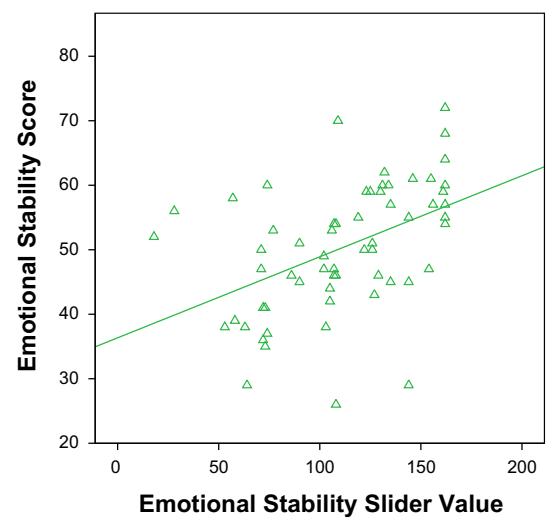

(e) Emotional Stability

Fig. 4 Correlation of Trait Score $\times$ Slider Values for the FFM personality traits 
Table 19 Means of study participants for the minimarkers scale

\begin{tabular}{llllll}
\hline Trait & Extraversion & Agreeableness & Conscientiousness & Emotional stability & Openness to experience \\
\hline Mean & 5.09 & 6.95 & 6.92 & 6.29 & 6.25 \\
\hline
\end{tabular}

Table 20 Partial correlations of each FFM trait on Minimarkers compared with the slider score, controlling for each other trait score on the non-target sliders

\begin{tabular}{llr}
\hline Partial correlations & $r$ & \multicolumn{1}{l}{$p$} \\
\hline Agreeableness & 0.57 & $<0.001$ \\
Extraversion & 0.75 & $<0.001$ \\
Emotional Stability & 0.34 & 0.010 \\
Conscientiousness & 0.61 & $<0.001$ \\
Openness to Experience & 0.36 & 0.006 \\
\hline
\end{tabular}

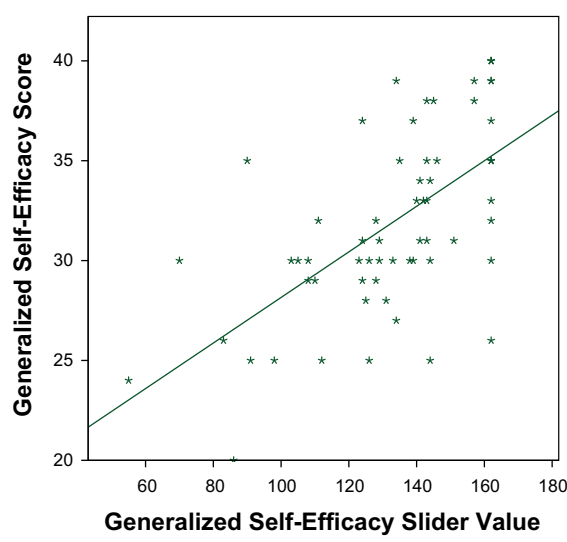

(a) Generalized self-efficacy

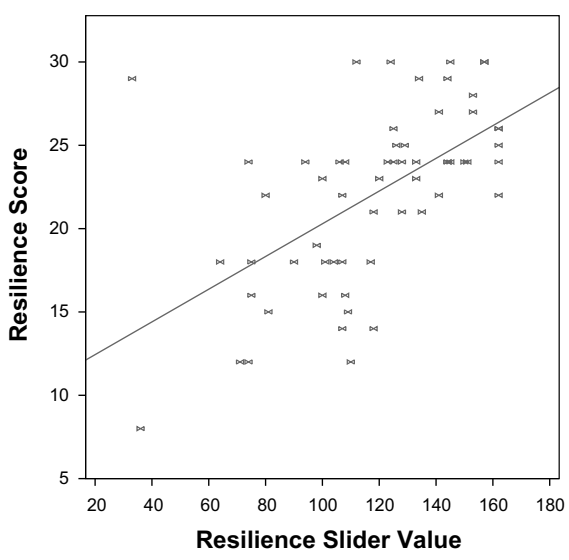

(b) Resilience

Fig. 5 Correlation of Trait Score $\times$ Slider Value for GSE and Resilience

To explore the inter-trait correlations within the FFM traits, a correlational analysis was run for the TIPI test for each FFM trait between Week 0 and Week 1 . The results are shown in Table 22. We found a similar pattern of correlation between non-target traits as we found in the sliders, with the TIPI test showing more correlations between non-target traits than the slider test. We can therefore see that the inter-trait correlations are captured by a validated personality test within our sample, and that the sliders show good test-retest reliability for target traits at Week 1.

Additionally, we used the data from Week 0 to repeat our validation experiment for the FFM sliders. A correlational analysis of FFM slider values $\times$ TIPI test scores showed a significant correlation between each trait's score on the slider test and TIPI test (E: $r=0.78, \mathrm{~A}: r=0.62, \mathrm{C}: r=0.62$, ES: $r=0.83$, O: $r=0.33 ; p<0.01$ for $\mathrm{E}, \mathrm{A}, \mathrm{C}$ and ES, $p<0.05$ for $\mathrm{O}$ ). These are similar to correlations reported in Table 18; $\mathrm{O}$ has a weaker correlation and ES has a stronger correlation in this reliability check. 
Table 21 Pearson's $r$ Correlation of the slider value of each pair of stories: FFM (E, A, C, ES, O), GSE and Resilience, repeated after 1 week

\begin{tabular}{|c|c|c|c|c|c|c|c|}
\hline \multirow[t]{2}{*}{ Wk 0 slider } & \multicolumn{7}{|c|}{ Wk 1 slider } \\
\hline & $\mathrm{E}$ & A & $\mathrm{C}$ & ES & $\mathrm{O}$ & GSE & RES \\
\hline E & $0.86 * *$ & 0.25 & 0.18 & $0.37 * *$ & 0.19 & $0.58 * *$ & $0.63 * *$ \\
\hline A & 0.18 & $0.83 * *$ & -0.08 & -0.23 & 0.10 & -0.07 & 0.06 \\
\hline $\mathrm{C}$ & -0.01 & -0.17 & $0.79 * *$ & 0.12 & -0.17 & $0.33^{*}$ & 0.21 \\
\hline ES & $0.32 *$ & 0.01 & $0.30 *$ & $0.86 * *$ & -0.11 & $0.56 * *$ & $0.46 * *$ \\
\hline $\mathrm{O}$ & 0.24 & 0.24 & 0.12 & $<0.01$ & $0.70 * *$ & 0.15 & $0.32 *$ \\
\hline GSE & $0.38 * *$ & 0.08 & $0.46 * *$ & $0.43 * *$ & 0.05 & $0.81 * *$ & $0.60 * *$ \\
\hline RES & $0.48 * *$ & 0.13 & $0.51 * *$ & $0.40 * *$ & 0.15 & $0.67 * *$ & $0.80 * *$ \\
\hline
\end{tabular}

Grey cells indicate the correlation of same trait at week 0 and week 1 ${ }^{*} p<0.05 ;{ }^{* *} p<0.01$

Table 22 Pearson's $r$ Correlation of the FFM TIPI test score (E, A, C, ES, O) at Week 0 and Week 1

\begin{tabular}{llllll}
\hline \multirow{2}{*}{ Wk 0 TIPI } & \multicolumn{4}{l}{ Wk 1 TIPI } \\
\cline { 2 - 6 } & E & A & C & ES & O \\
\hline E & $\mathbf{0 . 8 8}^{* *}$ & 0.19 & 0.08 & $\mathbf{0 . 3 1} *$ & $\mathbf{0 . 4 6}^{* *}$ \\
A & 0.18 & $\mathbf{0 . 8 3} * *$ & 0.23 & $<0.01$ & 0.26 \\
C & 0.06 & 0.08 & $\mathbf{0 . 8 4} * *$ & 0.09 & $\mathbf{0 . 3 4}$ \\
ES & $\mathbf{0 . 3 2}^{*}$ & 0.01 & 0.16 & $\mathbf{0 . 9 4} * *$ & -0.03 \\
O & $\mathbf{0 . 5 6}^{* *}$ & 0.08 & $\mathbf{0 . 3 0} *$ & -0.04 & $\mathbf{0 . 8 2} * *$ \\
\hline
\end{tabular}

Grey cells indicate the correlation of same trait at week 0 and week 1

${ }^{*} p<0.05 ; * * p<0.01$

\subsection{Interpreting slider values}

There are several possible strategies in the interpretation of the slider values for use in personality experiments. The slider values form a continuous variable, which can be used in analysis for further studies (e.g. using a regression analysis). Splitting data into distinct groups is often considered undesirable, as it causes the data to lose power (Irwin and McClelland 2003). However, for some studies it may be useful to use the slider values to divide participants into High and Low groups (for example, when you want to offer different content to people with different traits).

When choosing to divide participants into groups, it is important to consider statistical features of the data (e.g is the data statistically normal), as well as the purpose of the study, and the limitations of data collection. For non-normal data, data can be split using the median, tertiles or quartiles. For normal data, groups can be formed using the mean or standard deviation. A further option is to take the highest and lowest scoring participants to form a defined group size (e.g. top 50 and bottom 50), or to use a hybrid method (e.g. the top and bottom 20 participants at least 1 standard deviation from the mean). It is also possible to compute the equivalent score on a standardised test (e.g. the TIPI test), by using the regression formula generated at validation (e.g. in Table 18) and group by population normative data for that test, when available (e.g. Table 10). The choice should be guided by how much data 
Table 23 Summary of ways to divide Personality Slider data into groups

\begin{tabular}{|c|c|c|c|c|c|c|c|c|}
\hline & Regression & Median & Quartile & Tertile & Group size & Mean split & SD & Hybrid \\
\hline $\begin{array}{l}\text { Suitable for } \\
\text { non-normal data }\end{array}$ & $\checkmark$ & $\checkmark$ & $\checkmark$ & $\checkmark$ & & & & $\checkmark$ \\
\hline $\begin{array}{l}\text { Suitable for normal } \\
\text { data }\end{array}$ & $\checkmark$ & & & & $\checkmark$ & $\checkmark$ & $\checkmark$ & $\checkmark$ \\
\hline Groups equal size & & $\checkmark$ & $\checkmark^{\mathrm{a}}$ & $\checkmark$ & $\checkmark$ & & & $\checkmark$ \\
\hline $\begin{array}{l}\text { Distinct high/low } \\
\text { groups }\end{array}$ & $\checkmark$ & & $\checkmark$ & $\checkmark$ & $\checkmark$ & & $\checkmark^{b}$ & $\checkmark$ \\
\hline 'Normal' group & $\checkmark^{\mathrm{c}}$ & & $\checkmark$ & $\checkmark$ & & & $\checkmark$ & $\checkmark$ \\
\hline No data discarded & & & $\checkmark$ & $\checkmark$ & & $\checkmark$ & & \\
\hline $\begin{array}{l}\text { Groups reflect } \\
\text { population norms }\end{array}$ & $\checkmark$ & & & & & & & \\
\hline
\end{tabular}

${ }^{a}$ Double size normal group

${ }^{\mathrm{b}}$ Groups are statistically different from each other

${ }^{\mathrm{c}}$ Only possible if high and low thresholds are defined by other research

can be discarded, the importance of groups being distinct from each other, and how many groups are required (i.e. a 'neutral' group required). This is summarised in Table 23.

\subsection{Discussion}

This section has demonstrated how to use trait stories to measure personality. For each trait, there is a strong correlation between participants' scores on standardised personality tests and their scores on the slider scale (see Table 18). The effect size of the correlations imply that more polar trait stories (i.e. pairs of stories that are rated as very high and low in the trait) result in a sliding scale that better reflects the personality test. This can be seen in the comparatively low correlation for the Openness to Experience slider in Table 20. This highlights the importance of the story validation stage of development.

It should be noted that, while the sliders may be preferable to questionnaires, they have a lower accuracy than many standardised questionnaires. As for any decision about which measure to use in a study, the benefits of using the slider measure should be weighed against its lower accuracy; e.g. where high attrition needs to be mitigated by simplifying the questionnaires, or where the intended analysis groups users by trait.

\section{Applying stories and sliders in personality research and beyond}

This section provides examples of how the personality stories and sliders, and the method used to produce them, have been used in adaptation research, for adaptation to personality and beyond, demonstrating evidence of the method's usefulness. 
Table 24 Studies using personality stories and sliders to obtain or portray personality

\begin{tabular}{|c|c|c|c|c|}
\hline Use & References & Domain & Stories & Task \\
\hline \multirow[t]{7}{*}{ Portraying } & $\begin{array}{l}\text { Dennis et al. Dennis et al. } \\
\text { (2015) }\end{array}$ & Persuasion & FFM (C) & $\begin{array}{l}\text { Judge reminder } \\
\text { persuasiveness }\end{array}$ \\
\hline & $\begin{array}{l}\text { Dennis et al. (2012a, 2013, } \\
\text { 2016) }\end{array}$ & ITS & FFM & $\begin{array}{l}\text { Provide feedback and } \\
\text { emotional support }\end{array}$ \\
\hline & Dennis et al. (2011) & ITS & GSE & Provide feedback \\
\hline & Smith et al. (2015) & eHealth & FFM (ES) & Provide emotional support \\
\hline & Smith (2016) & eHealth & Resilience & Provide emotional support \\
\hline & Tintarev et al. (2013) & RecSys & $\mathrm{FFM}(\mathrm{O})$ & Select an item set \\
\hline & Okpo et al. (2016a, b, 2018) & ITS & Self-esteem & Select exercise difficulty \\
\hline \multirow[t]{4}{*}{ Obtaining } & Alhathli et al. $(2016,2017)$ & ITS & FFM & Judge learning materials \\
\hline & Smith and Masthoff (2018) & eHealth & FFM & $\begin{array}{l}\text { Judge emotional support } \\
\text { messages }\end{array}$ \\
\hline & Smith et al. (2016) & Persuasion & FFM & $\begin{array}{l}\text { Judge reminder } \\
\text { persuasiveness for a person } \\
\text { with their own personality }\end{array}$ \\
\hline & $\begin{array}{l}\text { Thomas et al. (2017); } \\
\text { Josekutty Thomas et al. } \\
\text { (2017) }\end{array}$ & Persuasion & FFM & $\begin{array}{l}\text { Judge healthy eating } \\
\text { messages }\end{array}$ \\
\hline
\end{tabular}

\subsection{Portraying personality}

Personality stories provide an easy way of portraying certain personalities as needed for indirect and user-as-wizard studies. Based on our research (i.e. Sect. 4), using personality stories also ensures (as far as possible) that the impression of the participant of the person's personality is in accordance to what the story is intended to express. Personality stories have been used for investigations into adaptation in persuasive technology, intelligent tutoring systems, and recommender systems (see Table 24). In Dennis et al. (2015) an indirect study was run with 68 participants investigating the impact of a skin cancer patient's personality on the perceived suitability of reminder messages (varied types based on Cialdini principles Cialdini 2001) to self-check their skin. Participants were provided with a personality story about a fictional skin cancer patient. They rated the suitability of reminder messages for this patient and selected the best message to use. Results showed a significant difference between participants based on levels of Conscientiousness: those high in Conscientiousness preferred authority messages as the second reminder whilst those low in Conscientiousness preferred scarcity messages.

In Dennis et al. (2016), five user-as-wizard studies were run with 1203 participants in total, each investigating the impact of one of the FFM personality traits (as well as performance) on feedback (emotional support and slant) given to a learner. Participants were provided with a personality story about a learner and their performance, and provided feedback. Based on this data, an algorithm was developed that adapted feedback to Conscientiousness and Emotional Stability. 
In Dennis et al. (2011), a User-as-Wizard study was run with 19 teachers, investigating the impact of GSE on feedback (slant). Participants were provided with a GSE personality story about a learner and their performance, and produced feedback. There was some evidence of teachers putting a positive spin on feedback for learners with a low GSE.

In Okpo et al. (2017), a User-as-Wizard study was run with 201 participants, investigating the impact of the Self-Esteem personality trait (as well as effort and performance) on exercise selection (difficulty level). Personality stories were constructed for Self-Esteem using the methodology presented in this paper. Participants were provided with either a low or high self-esteem story, the effort put in by the learner and their performance on a previous exercise. Participants selected the difficulty level of the next exercise for the learner to do. Self-esteem had an impact on difficulty level selection.

In Tintarev et al. (2013), a User-as-Wizard study was run with 120 participants, investigating the impact of Openness to Experience on recommendation diversity. Participants were provided with a personality story about a fictional friend as well as some indication of that friend's book preferences, and provided three book recommendations to this friend. There was some evidence that participants took Openness to Experience into account when producing the recommendations.

In Smith et al. (2015) and Smith (2016), two User-as Wizard studies were run with 61 and 45 participants respectively, investigating whether emotional support messages should be adapted to the recipient's Emotional Stability and Resilience respectively. Participants were provided with a personality story about a carer experiencing a stressful situation, and provided emotional support messages for this carer. Results showed that neurotic carers were provided with a wider range of emotional support. No effect was found of resilience on message selection.

\subsection{Obtaining personality}

Some studies require participants' personalities in order to analyse the impact of that personality on dependent variables (e.g. participants' preferences, participants' learning, etc). Most of the studies presented in Table 2 are of this type. The personality sliders have been used to obtain participants' personality to investigate adaptation in persuasive systems and intelligent tutoring systems. See Table 24 for example studies.

In Smith and Masthoff (2018), a study was run with 138 participants investigating the impact of personality on their appreciation of emotional support messages for stressful situations. Participants were told about a carer experiencing a stressful situation and rated an emotional support message provided by the carer's friend on how helpful, effective and sensitive they felt it was. Participants' FFM personality traits were obtained using personality sliders. Results showed that personality only had a small impact, with agreeableness and emotional stability warranting further investigation.

In Smith et al. (2016), an indirect study was run with 51 participants investigating the impact of personality on perceived persuasiveness of reminder messages (differing in type based on Cialdini principles Cialdini 2001) to self-check their skin for skin 
cancer patients. Participants' FFM traits were obtained using the personality sliders. They were told about a skin cancer patient who had the same personality as themselves and rated the suitability of reminder messages for this person. Results showed that personality is important when deciding on the type of persuasion to use in reminder messages.

In Thomas et al. (2017) and Josekutty Thomas et al. (2017), an indirect study was run with 152 participants investigating the impact of personality on the perceived persuasiveness of healthy eating messages differing in type and framing (positive or negative). Using the FFM personality sliders, the participants' personalities were obtained. They rated the perceived persuasiveness of messages for someone with a similar personality as themselves. There was some evidence of conscientiousness impacting persuasiveness.

In Alhathli et al. (2016), an indirect study was run with 50 participants exploring the impact of a learner's extraversion on the selection of learning materials (active vs passive, and social vs individual). Participants' personalities were obtained using the FFM personality sliders and they were told the learner had the same personality as them. They rated learning materials on the extent they felt the learner would enjoy them and they would increase the learner's skills and confidence. Extraversion was found to impact perceived enjoyment of social learning materials. In Alhathli et al. (2017), a similar study was run with 163 participants where the learning materials reflected learning styles, and participants' learning styles were measured in addition to their personality. No impact of either personality or learning style was found.

Results from these studies showed that the slider results can be used both for correlation analyses and to divide participants into high/low groups on different traits.

\subsection{Applying the method beyond personality research}

Finally, the method described in this paper for developing validated stories can also be applied to non-personality user or context characteristics. We have successfully applied this in multiple studies - for example, Smith et al. (2014) and Kindness (2014) developed stories that depicted different types of stressors experienced respectively by carers and community first responders. Forbes et al. (2014) developed stories that depicted different attitudes towards usage of transport means. In all of these cases, the stories were used to bootstrap adaptation research.

\section{Conclusion}

Increasingly, as illustrated in Sect. 2.4, research on adaptive systems is investigating personality as a user characteristic for adaptation. However, to do this effectively, reliable and lightweight ways are needed to express personality (for use in indirect and user-as-wizard studies) and to obtain user-personality. The paper makes two major contributions to this.

Firstly, the paper contributes a methodology for creating and validating stories that reliably express a personality trait. To illustrate the methodology, the paper presented 
the creation and validation of stories expressing the Five Factor model traits (extraversion, agreeableness, conscientiousness, emotional stability, openness to experience), generalized self-efficacy, and resilience. The usefulness of the personality stories for adaptation research has been shown by the many examples provided of their use for indirect and user-as-wizard studies (see Sect. 6).

Secondly, the paper contributes a lightweight methodology for obtaining userpersonality, using the personality stories as part of a self-assessment scale. These personality story scales can be used in studies investigating the impact of a trait, and may also be used by a system to allow it to adapt to this trait. The paper contributes guidelines on how to use such scales. The usefulness of the personality story scales for obtaining study participants' personality has been shown by their usage in adaptation studies (see Sect. 6).

While this paper looks at a small number of personality traits, the methodology can be extended to any user factor for which a validated questionnaire exists. So, as indicated in Sect. 6, this methodology has not only been been successfully used to produce additional stories for the personality trait self-esteem, but also to express user attitudes and stressors experienced. The more general methodology is the same as we used for personality (see Fig. 1), now using stories to express any characteristic.

There are several limitations and opportunities for future work. Firstly, the personality stories developed in this paper only portray a single trait. Although this enables investigations of the impact of such a trait, e.g on feedback to a learner, this does not facilitate investigations into interaction effects of multiple traits. To investigate this, stories which express two or more traits at the same time need to be developed.

Secondly, the stories developed in this paper only portrayed personality traits. We discussed above how the same method for constructing and validating stories has been used by us to portray other user and context characteristics such as stressors and user attitudes. We would like to extend this work by developing validated stories for portraying affective state, based on existing self-reporting affect scales. Similarly, we are interested in developing stories that reliably express other aspects such as learner performance and learner effort (a starting point towards the latter has been made in Okpo et al. (2017). When constructing such stories, care needs to be taken to avoid unintentionally evoking personality. For example, a learner who always performs well could be perceived as being highly conscientious, even when this was not the case. Another interesting area for validated story development may be to portray cultural differences (in line with Hofstede's work on cultural dimensions Hofstede 1983).

In summary, whilst there has been substantial research effort on obtaining userpersonality, there has been only very limited work on reliably expressing user personality. This paper has provided a methodology for doing so through validated personality stories, and has also shown that these stories can be used as an additional light-weight method for obtaining user personality.

Acknowledgements This paper acknowledges the Northern Research Partnership and the Scottish Informatics and Computer Science Alliance, who co-funded the Ph.Ds of the first two authors. This work was partially funded by: the RCUK Digital Economy award to the dot.rural Digital Economy Hub, University of Aberdeen, award reference EP/G066051/1; and the 'Affecting People with Natural Language' EPSRC platform grant, award reference EP/E011764/1. We thank Ana Ciocarlan for her help in investigating the 
reliability of the personality sliders, Jacek Kopecky for his help in the GSE validation study, and the anonymous reviewers for their constructive comments.

Open Access This article is distributed under the terms of the Creative Commons Attribution 4.0 International License (http://creativecommons.org/licenses/by/4.0/), which permits unrestricted use, distribution, and reproduction in any medium, provided you give appropriate credit to the original author(s) and the source, provide a link to the Creative Commons license, and indicate if changes were made.

\section{References}

Alhathli, M., Masthoff, J., Siddharthan, A.: Exploring the impact of extroversion on the selection of learning materials. In: Workshop on Personalization Approaches in Learning Environments (2016)

Alhathli, M., Masthoff, J., Siddharthan, A.: Should learning material's selection be adapted to learning style and personality? In: Adjunct Proceedings of UMAP Conference, pp. 275-280. ACM (2017)

Alkiş, N., Temizel, T.: The impact of individual differences on influence strategies. Pers. Individ. Dif. 87, 147-152 (2015)

Amichai-Hamburger, Y., Vinitzky, G.: Social network use and personality. Comput. Hum. Behav. 26(6), 1289-1295 (2010)

Anagnostopoulou, E., Magoutas, B., Bothos, E., Schrammel, J., Orji, R., Mentzas, G.: Exploring the links between persuasion, personality and mobility types in personalized mobility applications. In: Persuasive Technology'17, pp. 107-118. Springer (2017)

Appel, A.P., Candello, H., de Souza, B.S., Andrade, B.D.: Destiny: a cognitive mobile guide for the olympics. In: Proceedings of WWW'16, pp. 155-158 (2016)

Arteaga, S.M., Kudeki, M., Woodworth, A., Kurniawan, S.: Mobile system to motivate teenagers' physical activity. In: International Conference on Interaction Design and Children, pp. 1-10. ACM, NY, USA (2010)

Bachrach, Y., Kosinski, M., Graepel, T., Kohli, P., Stillwell, D.: Personality and patterns of facebook usage. In: Web Science, pp. 24-32 (2012)

Bandura, A.: Self-efficacy. Wiley Online Library, London (1994)

Bandura, A.: Exercise of Personal and Collective Efficacy in Changing Societies. Self-Efficiency in Changing Society of Australia. Cambridge University Press, Cambridge (1995)

Barrows, H.S.: Simulated (standardized) patients and other human simulations. Health Sciences Consortium (1987)

Biel, J.I., Gatica-Perez, D.: The youtube lens: crowdsourced personality impressions and audiovisual analysis of vlogs. IEEE Trans. Multimed. 15(1), 41-55 (2013)

Borgatta, E.F.: The structure of personality characteristics. Behav. Sci. 9(1), 8-17 (1964)

Braunhofer, M., Elahi, M., Ricci, F.: User personality and the new user problem in a context-aware point of interest recommender system. In: Information and Communication Technologies in Tourism 2015, pp. 537-549. Springer (2015)

Buss, A.H., Plomin, R.: Temperament: early developing personality traits. L. Erlbaum Associates Hillsdale, NJ (1984)

Calvo, R.A., D’Mello, S., Gratch, J., Kappas, A.: The Oxford Handbook of Affective Computing. Oxford Library of Psychology. Oxford University Press, Oxford (2015)

Cantador, I., Fernández-Tobías, I., Bellogín, A.: Relating personality types with user preferences in multiple entertainment domains. In: Workshop on Emotions and Personality in Personalized Services (2013)

Carlson, N.R., Martin, G.N., Buskist, W.: Psychology, 2nd edn. Pearson Education Ltd., London (2004)

Cattell, R.B.: Personality and Motivation Structure and Measurement. World Book Co., New York (1957)

Celli, F., Rossi, L.: The role of emotional stability in twitter conversations. In: Workshop on Semantic Analysis in Social Media, pp. 10-17. ACL (2012)

Chamorro-Premuzic, T.: Personality and Individual Differences, 2nd edn. BPS Blackwell, Oxford (2011)

Chen, G., Gully, S.M., Eden, D.: Validation of a new general self-efficacy scale. Organ. Res. Methods 4(1), 62-83 (2001)

Chen, J., Haber, E., Kang, R., Hsieh, G., Mahmud, J.: Making use of derived personality: the case of social media ad targeting. In: ICWSM (2015) 
Chen, L., Wu, W., He, L.: Personality and recommendation diversity. In: Tkalcic, M., De Carolis, B., de Gemmis, M., Odic, A., Košir, A. (eds.) Emotions and Personality in Personalized Services. HumanComputer Interaction Series. Springer, Cham (2016)

Cialdini, R.B.: Harnessing the science of persuasion. Harv. Bus. Rev. 79(9), 72-81 (2001)

Ciocarlan, A., Masthoff, J., Oren, N.: Qualitative study into adapting persuasive games for mental wellbeing to personality, stressors and attitudes. In: Adjunct Publication of UMAP'17, pp. 402-407. ACM (2017)

Ciocarlan, A., Masthoff, J., Oren, N.: Kindness is contagious: Study into exploring engagement and adapting persuasive games for wellbeing. In: Proceedings of the 26th Conference on User Modeling, Adaptation and Personalization, UMAP'18, pp. 311-319. ACM, New York, NY, USA (2018). https://doi.org/10. 1145/3209219.3209233

Ciocarlan, A., Masthoff, J., Oren, N.: Actual persuasiveness: impact of personality, age and gender on message type susceptibility. In: Proceedings of the Persuasive Technology Conference. Springer (2019)

Conati, C., Maclaren, H.: Empirically building and evaluating a probabilistic model of user affect. UMUAI 19(3), 267-303 (2009)

Connor, K.M., Davidson, J.R.: Development of a new resilience scale: the Connor-Davidson resilience scale (cd-risc). Depress Anxiety 18(2), 76-82 (2003)

Costa, P.T., McCrae, R.R.: NEO Personality Inventory-Form R (1985)

Costa, P.T., McCrae, R.R.: The revised neo personality inventory (neo-pi-r). In: The SAGE Handbook of Personality Theory and Assessment 2, pp. 179-198. SAGE Publications Inc (2008)

Cowley, B., Charles, D.: Behavlets: a method for practical player modelling using psychology-based player traits and domain specific features. UMUAI 26(2), 257-306 (2016)

de Vries, R.A., Truong, K.P., Evers, V.: Crowd-designed motivation: combining personality and the transtheoretical model. In: International Conference on Persuasive Technology, pp. 41-52. Springer (2016)

de Vries, R.A., Truong, K.P., Zaga, C., Li, J., Evers, V.: A word of advice: how to tailor motivational text messages based on behavior change theory to personality and gender. Pers. Ubiquitous Comput. 21(4), 675-687 (2017)

De Winter, J.C., Dodou, D.: Five-point likert items: t test versus Mann-Whitney-Wilcoxon. Pract. Assess. Res. Eval. 15(11), 2 (2010)

Dennis, M., Masthoff, J., Pain, H., Mellish, C.: Does self-efficacy matter when generating feedback? In: Biswas, G., Bull, S., Kay, J., Mitrovic, A. (eds.) Artificial Intelligence in Education, pp. 444-446. Springer, Berlin (2011)

Dennis, M., Masthoff, J., Mellish, C.: Adapting performance feedback to a learner's conscientiousness. In: UMAP, pp. 297-302. Springer (2012a)

Dennis, M., Masthoff, J., Mellish, C.: The quest for validated personality trait stories. In: IUI, pp. $273-276$. $\operatorname{ACM}(2012 b)$

Dennis, M., Masthoff, J., Mellish, C.: Does learner conscientiousness matter when generating emotional support in feedback? In: Affective Computing and Intelligent Interaction, pp. 209-214. IEEE (2013)

Dennis, M., Smith, K., Masthoff, J., Tintarev, N.: How can skin check reminders be personalised to patient conscientiousness? PATH Workshop (2015)

Dennis, M., Masthoff, J., Mellish, C.: Adapting progress feedback and emotional support to learner personality. Int. J. Artif. Intell. Educ. 26(3), 877-931 (2016)

DeYoung, C.G., Quilty, L.C., Peterson, J.B.: Between facets and domains: 10 aspects of the big five. J. Pers. Soc. Psychol. 93(5), 880 (2007)

Digman, J.M.: Classical theories of trait organization and the big five factors of personality. In: Annual Meeting of American Psychological Association, Atlanta, GA (1988)

Digman, J.M.: Personality structure: emergence of the five-factor model. Ann. Rev. Psychol. 41(1), 417-440 (1990)

Doce, T., Dias, J., Prada, R., Paiva, A.: Creating individual agents through personality traits. In: IVA, pp. 257-264. Springer (2010)

Donnellan, M.B., Oswald, F.L., Baird, B.M., Lucas, R.E.: The mini-IPIP scales: tiny-yet-effective measures of the big five factors of personality. Psychol. Assess. 18(2), 192 (2006)

Dunn, G., Wiersema, J., Ham, J., Aroyo, L.: Evaluating interface variants on personality acquisition for recommender systems. In: UMAP'09, pp. 259-270. Springer (2009)

Eysenck, H.J.: The Structure of Human Personality (Psychology Revivals). Routledge, Abingdon (2013)

Farnadi, G., Sushmita, S., Sitaraman, G., Ton, N., De Cock, M., Davalos, S.: A multivariate regression approach to personality impression recognition of vloggers. In: Proceedings of WCPR at ACMMM'14, pp. 1-6. ACM (2014) 
Farnadi, G., Sitaraman, G., Sushmita, S., Celli, F., Kosinski, M., Stillwell, D., Davalos, S., Moens, M.F., De Cock, M.: Computational personality recognition in social media. UMUAI 26(2), 109-142 (2016)

Fernández-Tobías, I., Braunhofer, M., Elahi, M., Ricci, F., Cantador, I.: Alleviating the new user problem in collaborative filtering by exploiting personality information. UMUAI 26, 221-255 (2016)

Ferwerda, B., Yang, E., Schedl, M., Tkalcic, M.: Personality traits predict music taxonomy preferences. In: CHI Ext. Abstracts, pp. 2241-2246. ACM (2015)

Fiske, D.W.: Consistency of the factorial structures of personality ratings from different sources. J. Abnorm. Soc. Psychol. 44(3), 329 (1949)

Forbes, P., Gabrielli, S., Maimone, R., Masthoff, J., Wells, S., Jylhä, A.: Towards using segmentation-based techniques to personalize mobility behavior interventions. ICST Trans. Ambient Syst. 1(4), e4 (2014)

Gao, R., Hao, B., Bai, S., Li, L., Li, A., Zhu, T.: Improving user profile with personality traits predicted from social media content. In: Recommender Systems, pp. 355-358. ACM (2013)

Golbeck, J., Robles, C., Turner, K.: Predicting personality with social media. In: CHI Extended Abstracts, pp. 253-262. ACM (2011)

Goldberg, L.: The structure of phenotypic personality traits. Am. Psychol. 48, 26-34 (1993)

Goldberg, L.R., Johnson, J.A., Eber, H.W., Hogan, R., Ashton, M.C., Cloninger, C.R., Gough, H.C.: The international personality item pool and the future of public-domain personality measures. J. Res. Pers. 40, 84-96 (2006)

Goolkasian, P.: The locus of control (2009). http://www.psych.uncc.edu/pagoolka/LC.html. Accessed 1 Mar 2019

Gosling, S.D., Rentfrow, P.J., Swann Jr., W.B.: A very brief measure of the big-five personality domains. J. Res. Pers. 37(6), 504-528 (2003a)

Gou, L., Mahmud, J., Haber, E., Zhou, M.: Personalityviz: a visualization tool to analyze people's personality with social media. In: Adj. Proceedings of IUI, pp. 45-46. ACM (2013)

Gow, A.J., Whiteman, M.C., Pattie, A., Deary, I.J.: Goldberg's ipip big-five factor markers: internal consistency and concurrent validation in scotland. Pers. Individ. Dif. 39(2), 317-329 (2005)

Grawemeyer, B., Mavrikis, M., Holmes, W., Gutiérrez-Santos, S., Wiedmann, M., Rummel, N.: Affective learning: improving engagement and enhancing learning with affect-aware feedback. User Model. User-adapt Interact. 27(1), 119-158 (2017)

Graziano, W.G., Jensen-Campbell, L.A., Finch, J.F.: The self as a mediator between personality and adjustment. J. Pers. Soc. Psychol. 73(2), 392 (1997)

Grumm, M., von Collani, G.: Measuring big-five personality dimensions with the implicit association test-implicit personality traits or self-esteem? Pers. Individ. Dif. 43(8), 2205-2217 (2007)

Guilford, J.P.: Factors and factors of personality. Psychol. Bull. 82(5), 802 (1975)

Halko, S., Kientz, J.A.: Personality and persuasive technology: an exploratory study on health-promoting mobile applications. In: International Conference on Persuasive Technology, pp. 150-161. Springer (2010)

Harland, P., Staats, H., Wilke, H.A.: Situational and personality factors as direct or personal norm mediated predictors of pro-environmental behavior: questions derived from norm-activation theory. Basic Appl. Soc. Psychol. 29(4), 323-334 (2007)

Harley, J.M., Carter, C.K., Papaionnou, N., Bouchet, F., Landis, R.S., Azevedo, R., Karabachian, L.: Examining the predictive relationship between personality and emotion traits and students' agent-directed emotions: towards emotionally-adaptive agent-based learning environments. UMUAI 26(2-3), 177219 (2016)

Hartman, R.O., Betz, N.E.: The five-factor model and career self-efficacy: general and domain-specific relationships. J. Career Assess. 15(2), 145-161 (2007)

Hirsh, J.B., Kang, S.K., Bodenhausen, G.V.: Personalized persuasion: Tailoring persuasive appeals to recipients' personality traits. Psychol. Sci. 23(6), 578-581 (2012)

Hjemdal, O., Vogel, P.A., Solem, S., Hagen, K., Stiles, T.C.: The relationship between resilience and levels of anxiety, depression, and obsessive-compulsive symptoms in adolescents. Clin. Psychol. Psychot. 18(4), 314-321 (2011)

Hofstede, G.: National cultures in four dimensions: a research-based theory of cultural differences among nations. Int. Stud. Manag. Organ. 13(1-2), 46-74 (1983)

Hogan, R.: Manual for the Hogan personality inventory (1986)

$\mathrm{Hu}, \mathrm{R}$., Pu, P.: Enhancing collaborative filtering systems with personality information. In: Proceedings of RecSys'11, pp. 197-204. ACM (2011) 
Iacobelli, F., Gill, A.J., Nowson, S., Oberlander, J.: Large scale personality classification of bloggers. In: Proceedings of ACII'11, pp. 568-577. Springer (2011)

Irwin, J.R., McClelland, G.H.: Negative consequences of dichotomizing continuous predictor variables. J. Mark. Res. 40(3), 366-371 (2003)

Jackson, D.N., Messick, S.: Content and style in personality assessment. Psychol. Bull. 55(4), 243 (1958)

John, O.P., Srivastava, S.: The Big Five trait taxonomy: history, measurement, and theoretical perspectives. In: Pervin, L.A., John, O.P. (eds.) Handbook of Personality. Elsevier (1999)

Josekutty Thomas, R., Masthoff, J., Oren, N.: Personalising healthy eating messages to age, gender and personality: using cialdini's principles and framing. In: Adj. Proceedings IUI, pp. 81-84. ACM (2017)

Judge, T.A., Erez, A., Bono, J.E., Thoresen, C.J.: Are measures of self-esteem, neuroticism, locus of control, and generalized self-efficacy indicators of a common core construct? J. Pers. Soc. Psychol. 83(3), 693710 (2002)

Kaptein, M., De Ruyter, B., Markopoulos, P., Aarts, E.: Adaptive persuasive systems: a study of tailored persuasive text messages to reduce snacking. TiiS 2(2), 10 (2012)

Kaptein, M., Markopoulos, P., de Ruyter, B., Aarts, E.: Personalizing persuasive technologies: explicit and implicit personalization using persuasion profiles. IJHCS 77, 38-51 (2015)

Kindness, P.: Designing emotional support for a virtual teammate aimed at alleviating stress. Ph.D. thesis, University of Aberdeen (2014)

Kompan, M., Bieliková, M.: Social structure and personality enhanced group recommendation. In: Proceedings of EMPIRE Workshop'14 (2014)

Koole, S.L., Jager, W., van den Berg, A.E., Vlek, C.A., Hofstee, W.K.: On the social nature of personality: effects of extraversion, agreeableness, and feedback about collective resource use on cooperation in a resource dilemma. Pers. Soc. Psychol. Bull. 27(3), 289-301 (2001)

Kosinski, M.: Mypersonality (2012). http://www.mypersonality.org. Accessed 1 Mar 2019

Kosinski, M., Bachrach, Y., Kohli, P., Stillwell, D., Graepel, T.: Manifestations of user personality in website choice and behaviour on online social networks. Mach. Learn. 95(3), 357-380 (2014)

Kulik, J.A.: Confirmatory attribution and the perpetuation of social beliefs. J. Pers. Soc. Psychol. 44(6), 1171 (1983)

Leontidis, M., Halatsis, C., Grigoriadou, M.: Using an affective multimedia learning framework for distance learning to motivate the learner effectively. Int. J. Learn. Technol. 6(3), 223-250 (2011)

Lepri, B., Staiano, J., Shmueli, E., Pianesi, F., Pentland, A.: The role of personality in shaping social networks and mediating behavioral change. UMUAI 26(2-3), 143-175 (2016)

LLC, T.P.: The big five personality test (2018). https://www.truity.com/test/big-five-personality-test. Accessed 1 Mar 2019

Loitsch, C., Weber, G., Kaklanis, N., Votis, K., Tzovaras, D.: A knowledge-based approach to user interface adaptation from preferences and for special needs. User Model. User-Adapted Interact. 27(3-5), 445491 (2017)

Lorr, M.: Interpersonal style inventory (ISI): Manual. Western Psychological Services (1986)

Luchins, A.S.: Definitiveness of impression and primacy-recency in communications. J. Soc. Psychol. 48(2), 275-290 (1958)

Magai, C., McFadden, S.: The Role of Emotions in Social and Personality Development. Plenum Press, New York (1995)

Masthoff, J.: The user as wizard: A method for early involvement in the design and evaluation of adaptive systems. In: Proceedings of UCDEAS, UMAP '06, vol. 1, pp. 460-469 (2006)

Masthoff, J.: Group Recommender Systems: Aggregation, Satisfaction and Group Attributes, pp. 743-776. Springer, Berlin (2015)

McCrae, R.R., Costa Jr., P.T.: A contemplated revision of the neo five-factor inventory. Pers. Individ. Dif 36(3), 587-596 (2004)

McCrae, R.R., John, O.P.: An introduction to the five-factor model and its applications. J. Pers. 60(2), 175-215 (1992)

McQuiggan, S., Mott, B., Lester, J.: Modeling self-efficacy in intelligent tutoring systems: an inductive approach. UMUAI 18(1-2), 81-123 (2008)

Mizgajski, J., Morzy, M.: Affective recommender systems in online news industry: how emotions influence reading choices. User Model. User-Adapt. Interact. (2018). https://doi.org/10.1007/s11257018-9213-x

Moncur, W., Masthoff, J., Reiter, E., Freer, Y., Nguyen, H.: Providing adaptive health updates across the personal social network. Hum. Comput. Interact. 29(3), 256-309 (2014) 
MT: Amazon mechanical turk. (2012). http://www.mturk.com. Accessed 1 Mar 2019

Nacke, L.E., Bateman, C., Mandryk, R.L.: Brainhex: a neurobiological gamer typology survey. Entertain. Comput. 5(1), 55-62 (2014). https://doi.org/10.1016/j.entcom.2013.06.002

Nguyen, T.T., Harper, F.M., Terveen, L., Konstan, J.A.: User personality and user satisfaction with recommender systems. Inform. Syst. Front. 20(6), 1173-1189 (2017)

Nguyen, H., Ruiz, C., Wilson, V., Strong, D., Djamasbi, S.: Using personality traits and chronotype to support personalization and feedback in a sleep health behavior change support system. In: Proceedings of HICSS'18 (2018)

Norman, W.T.: Toward an adequate taxonomy of personality attributes: replicated factor structure in peer nomination personality ratings. J. Abnorm. Soc. Psychol. 66(6), 574 (1963)

Nov, O., Arazy, O.: Personality-targeted design: theory, experimental procedure, and preliminary results. In: CSCW, pp. 977-984. ACM (2013)

Nov, O., Arazy, O., López, C., Brusilovsky, P.: Exploring personality-targeted UI design in online social participation systems. In: Proceedings of CHI'13, pp. 361-370. ACM (2013)

Nowson, S., Oberlander, J.: Identifying more bloggers. In: ICWSM (2007)

Nunes, M.A.S.N.: Recommender systems based on personality traits. Ph.D. thesis, Universite Montpellier 2 (2008)

Oberlander, J., Nowson, S.: Whose thumb is it anyway?: classifying author personality from weblog text. In: COLING/ACL, pp. 627-634 (2006)

Odić, A., Tkalčič, M., Tasic, J.F., Košir, A.: Personality and social context: impact on emotion induction from movies. In: Workshop on Emotions and Personality in Personalized Services (2013)

Okpo, J., Dennis, M., Masthoff, J., Smith, K.A., Beacham, N.A.: Exploring requirements for an adaptive exercise selection system. In: UMAP (Extended Proceedings) (2016a)

Okpo, J., Dennis, M., Smith, K.A., Masthoff, J., Beacham, N.: Adapting exercise selection to learner selfesteem and performance. In: Intelligent Tutoring Systems, p. 517. Springer (2016b)

Okpo, J., Masthoff, J., Dennis, M., Beacham, N., Ciocarlan, A.: Investigating the impact of personality and cognitive efficiency on the selection of exercises for learners. In: Proceedings of UMAP'17, pp. 140-147. ACM (2017)

Okpo, J.A., Masthoff, J., Dennis, M., Beacham, N.: Adapting exercise selection to performance, effort and self-esteem. New Rev. Hypermedia Multimed. 24(3), 1-32 (2018)

Orji, R., Vassileva, J., Mandryk, R.L.: Modeling the efficacy of persuasive strategies for different gamer types in serious games for health. UMUAI 24(5), 453-498 (2014)

Orji, R., Nacke, L.E., Di Marco, C.: Towards personality-driven persuasive health games and gamified systems. In: Proceedings of the 2017 CHI Conference on Human Factors in Computing Systems, pp. 1015-1027. ACM (2017)

Orji, R., Tondello, G.F., Nacke, L.E.: Personalizing persuasive strategies in gameful systems to gamification user types. Studies 61, 62 (2018)

O’Rourke, N., Kupferschmidt, A.L., Claxton, A., Smith, J.Z., Chappell, N., Beattie, B.L.: Psychological resilience predicts depressive symptoms among spouses of persons with Alzheimer disease over time. Aging Ment. Health 14(8), 984-993 (2010)

Oyibo, K., Orji, R., Vassileva, J.: Investigation of the influence of personality traits on Cialdini's persuasive strategies. In: Proceedings of PPT, Persuasive Technology'17 (2017)

Paramythis, A., Weibelzahl, S., Masthoff, J.: Layered evaluation of interactive adaptive systems: framework and formative methods. UMUAI 20(5), 383-453 (2010)

Park, G., Schwartz, H.A., Eichstaedt, J.C., Kern, M.L., Kosinski, M., Stillwell, D.J., Ungar, L.H., Seligman, M.E.: Automatic personality assessment through social media language. J. Pers. Soc. Psychol. 108(6), 934 (2015)

Peabody, D., Goldberg, L.R.: Some determinants of factor structures from personality-trait descriptors. J. Pers. Soc. Psychol. 57(3), 552 (1989)

Pelánek, R.: Bayesian knowledge tracing, logistic models, and beyond: an overview of learner modeling techniques. User Model. User-Adapt. Interact. 27(3-5), 313-350 (2017)

Perloff, R.M.: The Dynamics of Persuasion: Communication and Attitudes in the Twenty-First Century. Routledge, Abingdon (2010)

Piao, G., Breslin, J.G.: Inferring user interests in microblogging social networks: a survey. User Model. User-Adapt. Interact. 28(3), 277-329 (2018)

Polzehl, T.: Personality in Speech: Assessment and Automatic Classification. Springer, Berlin (2014) 
Quercia, D., Kosinski, M., Stillwell, D., Crowcroft, J.: Our twitter profiles, our selves: predicting personality with twitter. In: Proceeding of PASSAT, SocialCom'11, pp. 180-185 (2011)

Quercia, D., Lambiotte, R., Stillwell, D., Kosinski, M., Crowcroft, J.: The personality of popular facebook users. In: CSCW, pp. 955-964 (2012)

Quijano-Sanchez, L., Recio-Garcia, J.A., Diaz-Agudo, B.: Personality and social trust in group recommendations. In: International Conference on Tools with Artificial Intelligence, vol. 2, pp. 121-126. IEEE (2010)

Rammstedt, B., John, O.P.: Measuring personality in one minute or less: a 10-item short version of the big five inventory in English and German. J. Res. Pers. 41(1), 203-212 (2007)

Rao, D., Yarowsky, D.: Detecting latent user properties in social media. In: Proceedings of the NIPS MLSN Workshop, pp. 1-7. Citeseer (2010)

Rawlings, D., Ciancarelli, V.: Music preference and the five-factor model of the neo personality inventory. Psychol. Music 25(2), 120-132 (1997)

Robison, J., McQuiggan, S., Lester, J.: Developing empirically based student personality profiles for affective feedback models. In: Intelligent Tutoring Systems, pp. 285-295. Springer, Berlin (2010)

Rojas, M., Masip, D., Todorov, A., Vitria, J.: Automatic prediction of facial trait judgments: appearance vs. structural models. PloS ONE 6(8), e23,323 (2011)

Ross, C., Orr, E.S., Sisic, M., Arseneault, J.M., Simmering, M.G., Orr, R.R.: Personality and motivations associated with facebook use. Comput. Hum. Behav. 25(2), 578-586 (2009)

Rotter, J.: Generalized expectancies for internal versus external control of reinforcement. Psychol. Monogr. 80, 1-26 (1966)

Santos, O.C., Saneiro, M., Salmeron-Majadas, S., Boticario, J.G.: A methodological approach to eliciting affective educational recommendations. In: International Conference on Advanced Learning Technologies, pp. 529-533 (2014)

Santos, O.C., Saneiro, M., Boticario, J.G., Rodriguez-Sanchez, M.: Toward interactive context-aware affective educational recommendations in computer-assisted language learning. New Rev. Hypermedia Multimed. 22(1-2), 27-57 (2016)

Sarsam, S.M., Al-Samarraie, H.: Towards incorporating personality into the design of an interface: a method for facilitating users' interaction with the display. User Model. User-Adapt. Interact. 28(1), 75-96 (2018)

Saucier, G.: Mini-markers: a brief version of goldberg's unipolar big-five markers. J. Pers. Assess. 63(3), 506-516 (1994a)

Saucier, G.: Normative values for some large samples (1994b). https://pages.uoregon.edu/gsaucier/ MINIMARK.doc. Accessed 1 Mar 2019

Schiavo, G., Cappelletti, A., Mencarini, E., Stock, O., Zancanaro, M.: Influencing participation in group brainstorming through ambient intelligence. Int. J. Hum. Comput. Interact. 32(3), 258-276 (2016)

Schwarzer, R., Jerusalem, M.: Generalized self-efficacy scale. In: Weinman, J., Wright, S., M.J (eds.) Measures in health psychology: a user's portfolio. Causal and control beliefs, pp. 35-37. NFERNELSON (1995)

Smith, K.A.: Exploring personalised emotional support. Ph.D. thesis, University of Aberdeen (2016)

Smith, K.A., Masthoff, J.: Can a virtual agent provide good emotional support? In: Proceedings of 32nd BCS HCI Conference, Belfast, UK, 2018. BCS Learning and Development Ltd. (2018)

Smith, B.W., Dalen, J., Wiggins, K., Tooley, E., Christopher, P., Bernard, J.: The brief resilience scale: assessing the ability to bounce back. Int. J. Behav. Med. 15, 194-200 (2008)

Smith, B., Tooley, E., Christopher, P., Kay, V.: Resilience as the ability to bounce back from stress: a neglected personal resource? J. Posit. Psychol. 5(3), 166-176 (2010)

Smith, K.A., Masthoff, J., Tintarev, N., Moncur, W.: The development and evaluation of an emotional support algorithm for carers. Intell. Artif. 8(2), 181-196 (2014)

Smith, K.A., Masthoff, J., Tintarev, N., Moncur, W.: Adapting emotional support to personality for carers experiencing stress. In: International Workshop on Personalisation and Adaptation in Technology for Health-UMAP 2015 Adjunct Proceedings (2015)

Smith, K.A., Dennis, M., Masthoff, J.: Personalizing reminders to personality for melanoma self-checking. In: UMAP, pp. 85-93. ACM (2016)

Soldz, S., Vaillant, G.E.: The big five personality traits and the life course: a 45-year longitudinal study. J. Res. Pers. 33(2), 208-232 (1999) 
Soto, C.J., John, O.P.: The next big five inventory (bfi-2): developing and assessing a hierarchical model with 15 facets to enhance bandwidth, fidelity, and predictive power. J. Pers. Soc. Psychol. 113(1), 117 (2017)

Southwick, S.M., Charney, D.S.: The science of resilience: implications for the prevention and treatment of depression. Science 338(6103), 79-82 (2012)

Srivastava, S.: Measuring the big five personality factors (2012). http://psdlab.uoregon.edu/bigfive.html. Accessed 1 Mar 2019

Staiano, J., Lepri, B., Subramanian, R., Sebe, N., Pianesi, F.: Automatic modeling of personality states in small group interactions. In: International conference on Multimedia, pp. 989-992. ACM (2011)

Taylor, W.L.: Cloze procedure: a new tool for measuring readability. Journal. Q. 30, 415-433 (1953)

Tellegen, A.: Structures of Mood and Personality and Their Relevance to Assessing Anxiety, with an Emphasis on Self-Report. Lawrence Erlbaum Associates Inc, New Jersey (1985)

Thomas, K.W.: Thomas-kilmann conflict mode. TKI Profile and Interpretive Report, pp. 1-11 (2008)

Thomas, R., Masthoff, J., Oren, N.: Adapting healthy eating messages to personality. In: Persuasive Technology, pp. 119-132. Springer (2017)

Tintarev, N., Dennis, M., Masthoff, J.: Adapting recommendation diversity to openness to experience: a study of human behaviour. In: UMAP, pp. 190-202. Springer (2013)

Tkalčič, M., Chen, L.: Personality and recommender systems. In: Ricci, F., Rokach, L., Shapira, B. (eds.) Recommender Systems Handbook, pp. 715-739. Springer, Berlin (2015)

Tkalčič, M., Kunaver, M., Košir, A., Tasic, J.: Addressing the new user problem with a personality based user similarity measure. In: Proceedings of DEMRA Workshop at UMAP'11, p. 106 (2011)

Tkalčič, M., Quercia, D., Graf, S.: Preface to the special issue on personality in personalized systems. UMUAI 26(2), 103-107 (2016)

Tondello, G.F., Wehbe, R.R., Diamond, L., Busch, M., Marczewski, A., Nacke, L.E.: The gamification user types hexad scale. In: Proceedings of CHI PLAY'16, pp. 229-243. ACM (2016)

Tupes, E.C., Christal, R.E.: Recurrent personality factors based on trait ratings. J. Person. 60(2), 225-251 (1992)

Vinciarelli, A., Mohammadi, G.: A survey of personality computing. IEEE Trans. Affect. Comput. 5(3), 273-291 (2014)

Weinberg, J.D., Freese, J., McElhattan, D.: Comparing data characteristics and results of an online factorial survey between a population-based and a crowdsource-recruited sample. Sociol. Sci. 1, 292-310 (2014)

Wohn, D.Y., Wash, R.: A virtual "room" with a cue: detecting personality through spatial customization in a city simulation game. Comput. Hum. Behav. 29(1), 155-159 (2013)

$\mathrm{Wu}, \mathrm{W}$., Chen, L.: Implicit acquisition of user personality for augmenting movie recommendations. In: UMAP, pp. 302-314. Springer (2015)

Wu, W., Chen, L., Zhao, Y.: Personalizing recommendation diversity based on user personality. User Model. User-Adapt. Interact. 28(3), 237-276 (2018)

Yee, N., Ducheneaut, N., Nelson, L., Likarish, P.: Introverted elves and conscientious gnomes: the expression of personality in world of warcraft. In: CHI, pp. 753-762. ACM, New York, NY, USA (2011)

Youyou, W., Kosinski, M., Stillwell, D.: Computer-based personality judgments are more accurate than those made by humans. Proc. Natl. Acad. Sci. 112(4), 1036-1040 (2015)

Zeng, Z., Pantic, M., Roisman, G.I., Huang, T.S.: A survey of affect recognition methods: audio, visual, and spontaneous expressions. IEEE Trans. Pattern Anal. Mach. Intell. 31(1), 39-58 (2009)

Zhang, C., Conrad, F.: Speeding in web surveys: the tendency to answer very fast and its association with straightlining. Surv. Res. Methods 8, 127-135 (2014)

Publisher's Note Springer Nature remains neutral with regard to jurisdictional claims in published maps and institutional affiliations.

Kirsten A. Smith is a research fellow at the University of Southampton working across Psychology and Primary Care. Her Ph.D. in Computing Science (completed in 2016 at the University of Aberdeen) investigated how a computer application could provide better emotional support for carers, by providing personalised emotional support messages and mediating communication between the carer and their personal social network. As part of the LifeGuide Team, she has worked on digital behaviour change interventions for lifestyle changes after cancer treatment and preventing cognitive decline in older adults. She 
is currently involved in the Empathica Project: a digital intervention to train GPs in empathy to improve patient wellbeing.

Matt Dennis is a lecturer at the University of Portsmouth (UK). His research interests lie in designing and developing intelligent systems which adapt to user characteristics, particularly personality and affect. His Ph.D. (University of Aberdeen, 2014) investigated how feedback given by an intelligent conversational agent could be tailored to learner personality and prior performance. He has also collaborated on projects in the healthcare domain, such as emotional support for Community First Responders and the personalization of reminders for melanoma skin checking.

Judith Masthoff is a chair in Interaction Technology at Utrecht University and in Computing Science at the University of Aberdeen. Her research focuses on personalization. She has applied this in a broad range of areas including recommender systems, intelligent user interfaces, intelligent tutoring systems, persuasive technology, and affective computing. She is Editor in Chief of the User Modeling and User-Adapted Interaction journal and a director of User Modeling Inc., the professional association of user modeling researchers.

Nava Tintarev is an Assistant Professor and Technology Fellow at Delft University of Technology. She completed her Ph.D. at the University of Aberdeen in 2010. Her research looks at how to improve the transparency and decision support for recommender systems. She in on the management team for Delft Design for Values, and is contributing to bringing together, integrating, and expanding existing practices and expertise for responsible data science. She acts as a senior member of the program committee for the ACM Conferences on Intelligent User Interfaces, Recommender Systems, and User Modeling Adaptation and Personalization. She will serve as a Program co-Chair for the Intelligent User Interfaces conference in 2020 . 